\title{
Why a New Name? The Role of Asset Characteristics and Broad Market Trends in Predicting Brand Affiliation Change in Hotels
}

Cornell Hospitality Quarterly 202I, Vol. 62(2) 173-197 (c) The Author(s) 2020 Article reuse guidelines: sagepub.com/journals-permissions DOI: 10.1 177//1938965520924648 journals.sagepub.com/home/cqx (S)AGE

\author{
Isabella Blengini' and Prashant Das (D) I,2
}

\begin{abstract}
Brand affiliation is a critical choice in the hotel business. The decision to change brand (i.e., "rebranding") may be determined by asset-level private information as well as publicly known information related to the property. In this article, we focus on nonprivate information, such as property features as well as market and industry performance indicators. Using the semiparametric and parametric hazard models, we show that variables such as hotels' past record of affiliation changes, age, class, type, and location help predict the likelihood of rebranding. This analysis should increase the ability of industry practitioners to define rebranding risk and to use it as a competitive advantage.
\end{abstract}

\section{Keywords}

affiliation; brand change; commercial real estate; hotels; hazard rate

\section{Introduction}

\section{Hotel Rebranding: A Fast-Growing Trend}

Operated independently, or through a franchise or management contract, a hotel's brand identity is critical in its performance and valuation. ${ }^{1}$ Also, changing a hotel's brand ("rebranding," or "affiliation change") is a costly affair as a hotel must incur additional expenses to meet the new brand standards. Besides, premature termination of an existing brand contract leads to additional, contractual expenses. Yet, rebranding is emerging as a strong trend in the hotel industry. Between 1990 and 2017, the United States witnessed rebranding in more than 11,000 hotels (approximately 1.7 million rooms). Since 2011, on average, 1,200 hotels (110,000 rooms) have been rebranded annually. Between 1990 and 2017, 32\% of hotels in the United States were rebranded at least once, with some changing their brands up to 7 times. $^{2}$

The market for hotel branding is fast expanding (see Figure 1). The proportion of independent hotels adopting chain-affiliated brands tripled in the 25 years between 1992 and 2017. In terms of numbers, the growth was seven- to eightfold: from 57 hotels (4,445 rooms) in 1992 to 371 hotels (36,074 rooms) in 2017. Besides, as brands are expanding faster than the hotel supply, the market for rebranding is increasingly competitive (hotel supply has grown only at a $2 \%$ annual rate, but the number of independent hotels adopting brand affiliations ${ }^{3}$ has grown by $8 \%$.
More important, between 1992 and 2017, more than 5,000 hotels ( 0.6 million rooms) changed their affiliation from one chain to another (i.e., a growth rate of $9 \%$ per year ${ }^{4}$ ). In other words, the proportion of hotels ${ }^{5}$ changing their brand affiliation from one chain to another has tripled: from $0.2 \%$ in 1992 to $0.6 \%$ in 2017 . According to our estimates, nearly $\$ 500$ million worth of brand contracts were transferred across hotel chains in 2018 alone.

\section{Existing Theory and What We Do Not Know}

Past studies (such as Hanson et al., 2009; Tsai et al., 2015) have focused on the effects of rebranding on hotels from owners' perspective: Despite the high costs, rebranding often improves - or at least does not worsen - the financial performance of a hotel. For owners, rebranding is a risk worth taking, a rationale also reflected in the recent trends discussed above. Brand positioning, however, is one of the many critical determinants of a hotel's operational and financial performance, which are mostly explained by several other factors. ${ }^{6}$ For hotel chains, rebranding is a substantially more critical

'EHL-HES.SO, University of Applied Sciences and Arts Western

Switzerland, Lausanne, Switzerland

${ }^{2}$ Indian Institute of Management Ahmedabad, India

\section{Corresponding Author:}

Prashant Das, Route de Cojonnex 18, Lausanne, VD 1000, Switzerland. Email:Prashant.pkd@gmail.com 


\section{Brand Change Trends | Unit: Room}

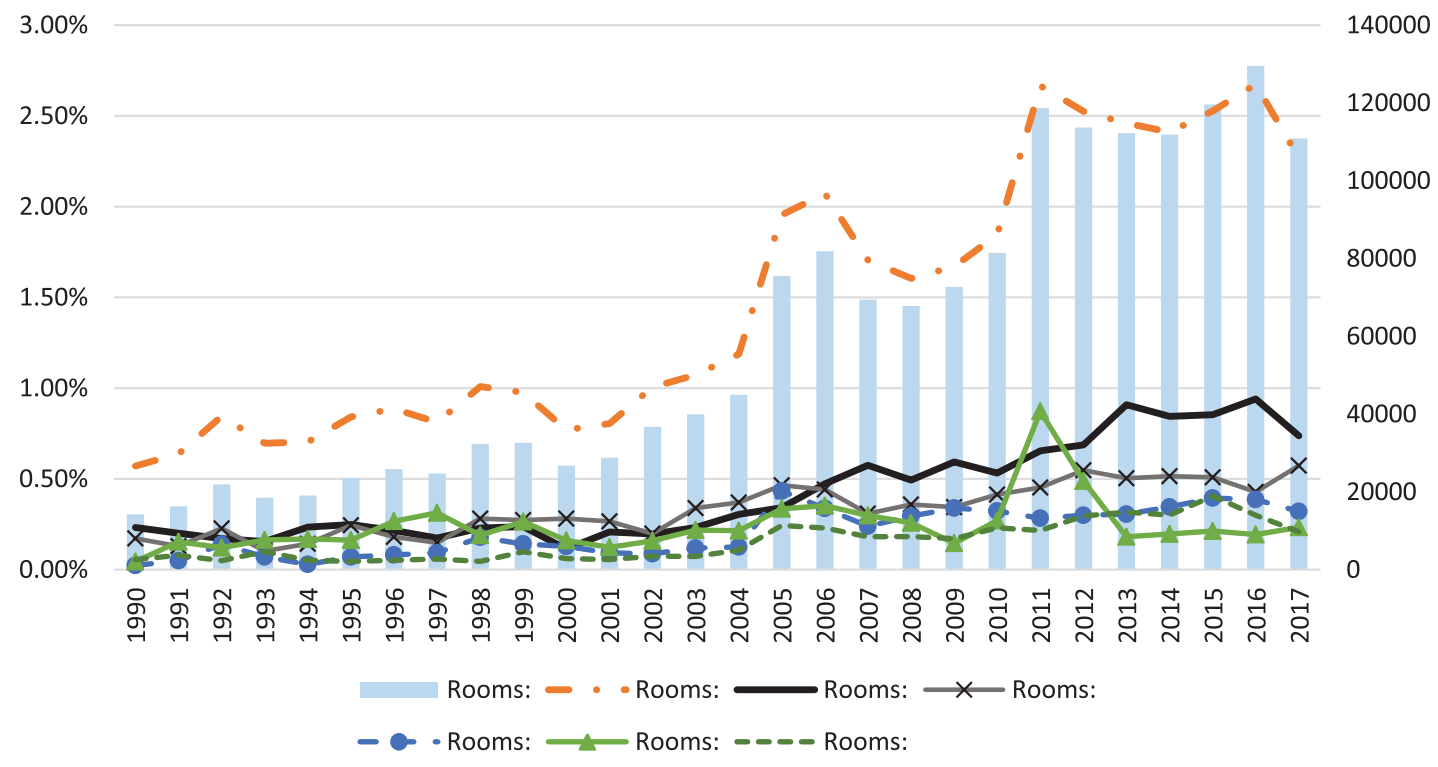

\section{Figure 1.}

Percentage of Rooms Rebranding Over the Total, Between 1990 and 2017.

phenomenon: Each brand contract (with a hotel) implies a long-term revenue stream, and an important source of growth. According to our estimates, the value of a new brand contract in 2018 was nearly $\$ 12,000$ to $\$ 15,000$ per room. ${ }^{7}$ Thus, the rebranding market during this year amounted to roughly $\$ 5$ to $\$ 7$ billion. If the rebranding trends persist, by 2030, rebranding will add a total of around $\$ 100$ billion capitalized value to large chains alone. Clearly, any type of brand repositioning (i.e., independent to brand, brand to independent, one brand to another within or across chains) —which we generally call "rebranding," is a strategic event for a chain. ${ }^{8}$

On one hand, bringing an independent (or differently affiliated) hotel to its own brand portfolio is a strategic success to hotel chains. On the other hand, losing a hotel to another chain (or to independent status) is a costly "hazard" in the competitive market of hotel chains. To manage the impact of this hazard, a chain must estimate the extent of the risk. Therefore, the strategic importance of rebranding - and its predictability - is critical to the strategy of hotel chains. Predicting a hotel's propensity to rebrand itself is the focal theme of our study. Our knowledge about the predictors of rebranding, at the individual hotel level in particular, is limited and mostly anecdotal. This study answers a more fundamental question: Can we predict a hotel's propensity to rebrand? This study complements the existing literature that describes the effects of rebranding by focusing on the predictors of rebranding. In particular, we develop hazard models that predict a hotel's propensity to rebrand. We also develop accelerated failure time models that estimate the survival time of a hotel's existing brand.

\section{Why This Study?}

A critical step for owners and operators - to strategize on rebranding (or manage the risk of rebranding) - is to first assess the incidence (or hazard) of rebranding at the asset level. However, our predictive knowledge about rebranding activity is severely limited. This study fills this critical knowledge gap by showing how hotel attributes and specific macroeconomic factors could predict the rebranding of a hotel. The results of this study should be interesting not only for industry practitioners, but also for the scholarly audience. Hotel chains could apply our models to identify hotels that have a high likelihood of rebranding. For example, the models can predict which independent hotel is prone to be branded by a chain, or which hotel is likely to switch its brand from one chain to another. Applying such models to a chain's existing portfolio of hotels will help them measure the risk of rebranding hazard. Applying them to hotels beyond their portfolio will provide a powerful tool to identify potential targets for signing brand contracts. Similarly, property owners could estimate the rebranding propensity of their competitors and act preemptively.

Unlike past studies, which have analyzed relatively smaller samples of hotels (and have focused mainly on hotels' financial performance after rebranding), we investigate whether hotels have some inherent propensity to 
rebrand purely based on their own observable attributes: physical, geographic, and contractual. In addition, we include macroeconomic variables in the analyses to explain how the rebranding propensity is influenced by time-varying external conditions. We show that a large part of rebranding can be explained by individual asset characteristics and time-varying market trends. In addition, we show how optimism (or pessimism) in the financial markets propels the affiliation change.

The remainder of the article is structured as follows. Next, we provide a brief survey of background literature in this area. Then, the section "Theoretical Framework" describes the theoretical framework of our analysis. The following sections sequentially describe the data, empirical method, and findings. Afterward, we conduct some robustness tests and present a simple, predictive model for the brand survival time. In the final section, we draw our conclusions, outline limitations, and offer ideas for potential extensions of our study.

\section{Related Literature}

\section{Effects of Rebranding}

Tsai et al. (2015) show rebranding as an important strategic decision that can be initiated either by the owner of the property or by the franchisor. The study reports that several factors are associated with rebranding, such as a change in business model, franchisor/franchisee disagreement, changes in franchise fees, the need to address a shift in the local demand, or simply the expiration of an existing franchise contract. However, existing literature on rebranding is limited and has focused mainly on the effects of brand changes, rather than on its determinants. For example, Tsai et al. (2015) analyze the effects of a brand change on the financial performance of a hotel, suggesting that, in general, rebranding results in an increase in the occupancy rate of hotels. In contrast, Hanson et al. (2009) conclude that the choice of rebranding does not significantly change financial ratios, when the scale does not change. Instead, hotels that rebrand experience a temporary decline in hotel net operating income (NOI), followed by a gradual recovery. However, hotels that moved upscale experienced an increase in average daily room (ADR) rate, while those that downscaled did not experience any significant reduction in ADR. Hanson et al. (2009) notes that a vast majority of the hotels in their sample decided to downscale, to respond to age and increased competition. This strategy is effective in difficult environments as hotels could rebrand without reducing their results. Hanson et al. (2009) emphasize that to benefit financially from an affiliation change, a hotel must also move upscale, not laterally within the same scale. Those who upscaled or did not rescale at all (particularly when moving laterally within a brand family) did not reap similar financial rewards. Dev (2015), on the contrary, reports that brand conversion only leads to significant financial benefits if the new brand ensures relative strength and a good fit with the property.

\section{Independent Versus Branded Hotels}

O'Neill and Mattila (2010) show evidence that branded hotels are preferred by loan underwriters compared with independent hotels. In the context of retail properties, Rosiers et al. (2016) report that compared with independent or local-chain stores, owners of superior quality chain stores enjoy rental premiums. O'Neill et al. (2008) find that marketing and payroll expenses have no significant association with revenues or profits in independent hotels, unlike other segments. O'Neill and Carlbäck (2011) compare the performance of independent hotels and chains during the full business cycle. They find that branded and independent hotels behave similarly in terms of NOI in expansionary phases, while branded hotels perform significantly better than independent hotels in contractionary phases. Those findings, associated with the property features that we identify, help us better understand the choice to change business model.

To sum up, the phenomenon of rebranding has been studied in terms of its effects on performance. The literature in general finds that rebranding allows the hotel either to improve its performance or to maintain its previous results. In other terms, rebranding can be interpreted either as a desire to improve the financial performance of a hotel or as a necessity to safeguard its performance against odds such as age, new supply, and competition. In our study, we build on these findings to understand whether specific property attributes correlate with the propensity to change affiliation.

\section{Theoretical Framework}

Empirical literature has shown that a desire to maintain, or improve, the financial results of a property is the main motivation for rebranding. As such, financial performance must be incorporated into predictive models of rebranding. However, property-level financial performance data are scarce and proprietary. Nevertheless, a large body of literature on hedonic pricing of commercial assets has shown that property valuation as well as financial performance (occupancy rates, Revenue per Available Room [RevPAR], average daily rate $[\mathrm{ADR}]$, and net operating income [NOI]) are mostly determined by a property's observable attributes. $^{9}$ Indeed, models that include these attributes inherently will control for the financial performance in empirical models. The goal of this article is to analyze whether these observable hotel characteristics can be used to anticipate the particular hotel's rebranding strategy. ${ }^{10}$ 
Consider an infinite time horizon model. The hotel manager maximizes the present discounted value of its future NOI stream:

$$
\max \sum_{t=0}^{\infty} \frac{N O I_{t}}{(1+r)^{t}},
$$

where $N O I_{t}=R_{t}-C_{t}$. The variable $R_{t}$ stands for revenue, while $C_{t}$ represents total operating costs (realized or allocated). Following Corgel et al. (2015), we assume that NOI, revenue, and costs can be expressed as the sum of two components: a market component $(\mathrm{m})$ and an idiosyncratic component specific to the hotel $(i)$ :

$$
N O I_{t}=N O I_{m, t}+N O I_{i, t}=\left(R_{m, t}+R_{i, t}\right)-\left(C_{m, t}+C_{i, t}\right)
$$

Solving this maximization problem, we can identify a stream of optimal values of net operating income, $\mathrm{NOI}_{t}^{*}$, which varies over time. We model the choice of rebranding as the result of a comparison between observed (realized) net operating income $\left(N O I_{t}\right)$ and the optimal (theoretical) net operating income at time $t\left(\mathrm{NOI}_{t}^{*}\right)$. A hotel chooses to rebrand whenever its performance is inferior to its optimal (potential) one:

$$
\begin{gathered}
\mathrm{NOI}_{t}<\mathrm{NOI}_{t}^{*} . \\
\text { Also, } \mathrm{NOI}_{t}=X \beta+\varepsilon_{t},
\end{gathered}
$$

where, $\mathrm{X}$ is a vector that has both market (systematic) variables and property-specific attributes affecting the hotel performance at time $t, \beta$ is the set of parameters associated with these variables, and $\varepsilon_{t}$ is an idiosyncratic error.

Rebranding is observed when,

$$
X \beta+\varepsilon_{t}<N O I_{t}^{*}
$$

which implies that,

$$
\varepsilon_{t}<N O I_{t}^{*}-X \beta
$$

Assuming that the noise $\varepsilon_{t}$ is symmetrically distributed around zero, the probability of rebranding $(\operatorname{Pr})$ is,

$$
\begin{aligned}
\operatorname{Pr}(\text { rebranding }) & =G\left(N_{\left.N O I_{t}^{*}-X \beta\right)}\right. \\
& =G\left(X \beta-N O I_{t}^{*}\right)=G\left(X \beta^{*}\right)
\end{aligned}
$$

where, $G$ is a generic cumulative distribution function, and the vector of parameters $\beta^{*}$ is $\beta$ rescaled by the value $N O I_{t}^{*}$. In other words, the probability of rebranding depends on the probability that the performance of the hotel is inferior to the optimal (potential) one, which, in turn, is a function of market variables and specific hotel features. Our empirical models follow this hypothesis. We use survival analysis to identify and study the variables that increase the probability of rebranding.

\section{Data}

Our dataset is primarily based on the U.S. Hotel Census provided by STR, a division of Co-Star Global, a data analytics company. The sample was collected in December 2017 and includes nearly 66,000 hotels. For each hotel, STR provides a rich set of nearly 100 attributes, including a hotel's physical attributes (age, amenities, size, number of floors, etc.), location (street address, market classifications), hotel-business characteristics (room pricing, class, operational structure), current brand affiliation, details on the current owner, and history of past affiliation changes. We excluded nearly 15,000 properties from our study due to missing data on age or size (i.e., number of rooms). The decision to change the brand affiliation is a function of the existing affiliation (exaffiliation) and the attributes of the hotel at that time. Nearly 1,800 hotels for which we could not identify the ex-affiliation scale were also removed. ${ }^{11}$ Besides, it is likely that the hotel attributes may have been substantially different for those whose most recent affiliation change took place a long time ago. Therefore, in our dataset, the oldest rebranding by a hotel does not precede 1990. Finally, our dataset includes 43,041 hotels. For a detailed data summary and description, please refer to Table 1 .

The average hotel in our sample is 28 years old with 101 rooms and four (3.74) floors. A total of $2 \%$ have convention facilities, $15 \%$ of the hotels are of the all-suite category, whereas $2 \%$ are boutique hotels. A majority of these hotels are located in small metros/towns $(28 \%)$ or suburban $(35 \%)$ locations. Interstate (highway), urban, resort, and airport locations have $14 \%, 10 \%, 8 \%$, and $5 \%$ representations, respectively. Throughout their lifetime, these hotels experienced 41,442 affiliation changes in total ( 0.84 per hotel). However, $68 \%$ of the hotels never changed their affiliation $(\overline{\text { REBRANDING }}=0.32)$. The remainder rebranded between 1 and 4 times during their lifetime. NX refers to the number of affiliation changes before the most recent change, hence, ranging between zero and three. The hotel characteristics provided by our data provider - that we posit as the determinants of affiliation change - are primarily for the present times. Therefore, we focus on the most recent affiliation change of a hotel to avoid capturing attributes that may not be directly associated with (past) rebranding events. As a result, the event ("hazard") date for $32 \%$ of the hotels is the date of the most recent affiliation change. For other hotels (the "censored observations"), the state was recorded on December 15, 2017, the date of our data collection.

In total, $10 \%$ rebrandings refer to the change from an independent hotel to branded (I2B). Some 7\% refer to branded 


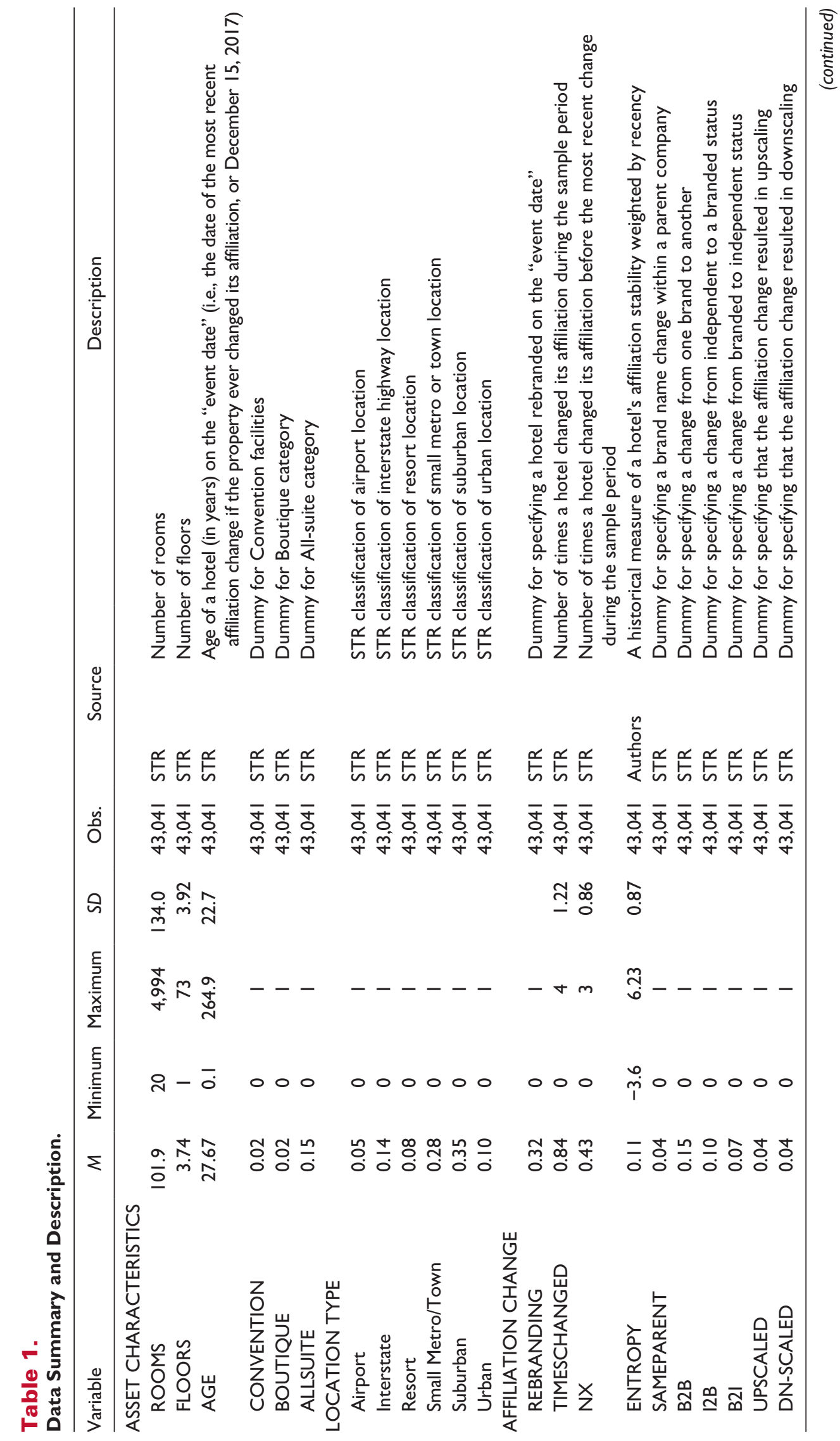




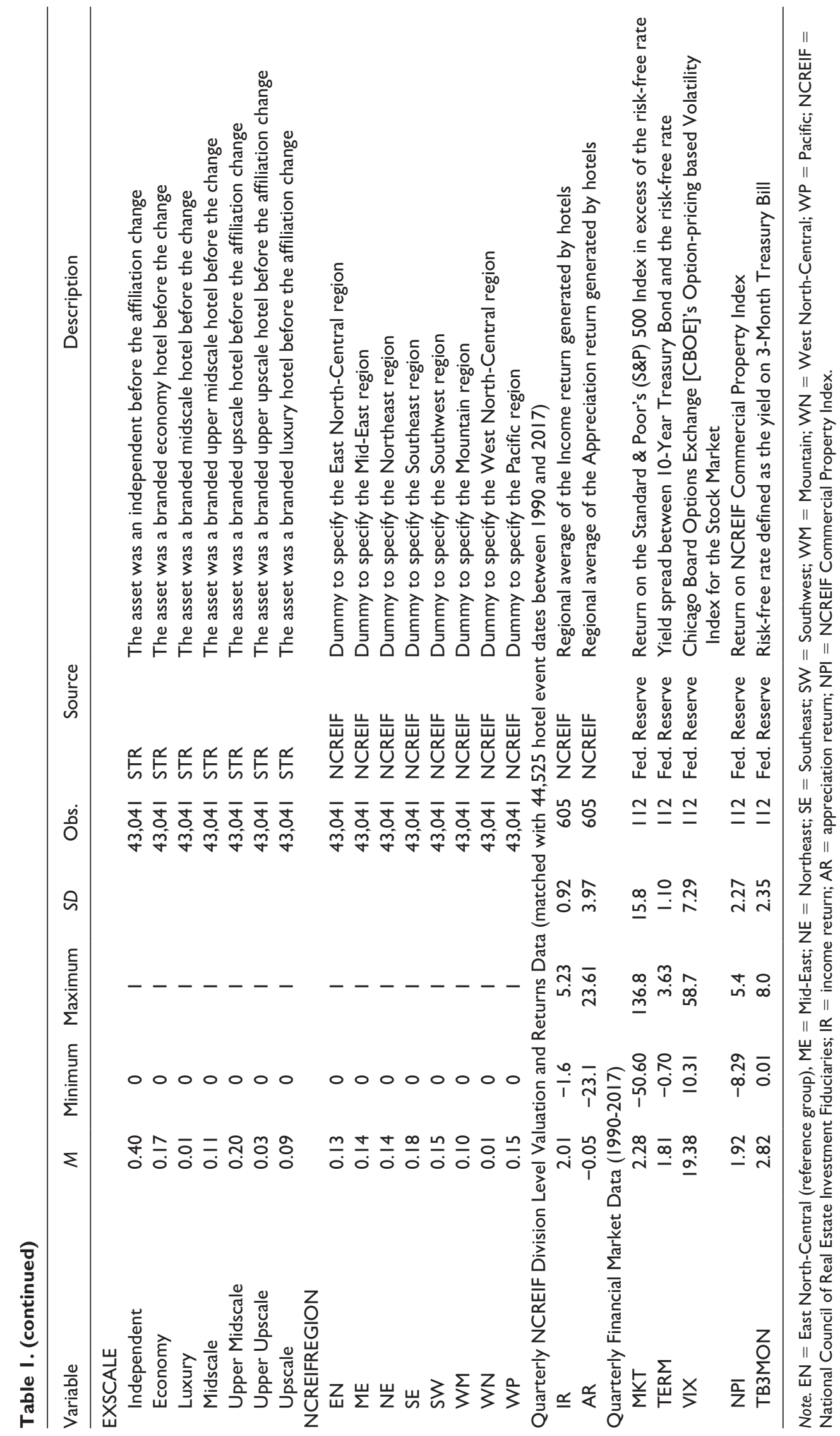


hotels turning independent (B2I). Whereas $22 \%$ of the affiliation changes were within scales, $4 \%$ each were either downscaled or upscaled. In terms of the ex-affiliation (i.e., the affiliation right before the most recent change), independent hotels represent $40 \%$ of the hotels in the sample, while chains represent the remaining $60 \%$. Chains are classified as uppermidscale (20\%), economy (17\%), midscale (11\%), upscale (9\%), upper upscale $(3 \%)$, and luxury (1\%) segments. Geographically, the hotels in our sample are evenly distributed across the eight regions, representing between $18 \%$ in the Southeast (SE) to $10 \%$ in the West North-Central regions.

To measure the hotel market financial performance, we map each hotel in our sample to one of the geographic regions. ${ }^{12}$ For each region, National Council of Real Estate Investment Fiduciaries (NCREIF) ${ }^{13}$ provides aggregated quarterly returns data. These returns data are time weighted. In particular, we extract the quarterly income return (IR: based on hotel cash flows) and appreciation return (AR: based on hotel valuation) data for each hotel matching its rebranding (the "hazard" event) date. During our period of analysis, we have 605 observations of IR and AR, which vary substantially across time and regions, IR $[-1.6 \%, 5.23 \%]$ and AR $[-23.1 \%, 23.61 \%]$. Also, at the national level, we collect quarterly financial market data. MKT is the return on the stock market in excess of the risk-free rate. The higher the MKT, the higher the stock market performance. Very high MKT may also signal a bubble. TERM reflects the "yield curve" measured by the yield spread between long-term and short-term treasury securities. A healthy market expects an upward sloping yield curve (thus, a larger value of TERM). Smaller values of TERM signal market distress or bust. VIX is the measure of option-implied volatility on the stock exchange. High values of VIX are interpreted as "fear" in the stock market. NPI is the return on commercial real estate. T3MON is the yield on 3-month Treasury Bill also referred to as the risk-free rate.

\section{The Degree of Disarray in Brand Positioning: Entropy}

In our sample, the average survival time of an affiliation is 13 years (including censored observations ${ }^{14}$ ). The past record of affiliation change in a hotel could signal a property's unobserved characteristics that could influence its propensity to change affiliation in the future. However, the past record of affiliation changes may be a composite of several factors: how many times a hotel changed its affiliation in the past and how long each of the past affiliations survived. Besides, the past changes also build a heuristic perception of a hotel's propensity to change affiliations.

The perceived degree of "disarray" in the affiliation stability of a hotel could be estimated combining these three measures. In our study, we posit the measure ${ }^{15}$ as a memory-weighted historical record of affiliation "disarray" in a hotel. As our measure of affiliation change disarray loosely mimics the "entropy" measure usually applied in social sciences and physics, we name this measure as such. This entropy reflects how often a hotel changed affiliation in the past, how recent the changes are, and how long these affiliations survived. The entropy measure can be interpreted in a relative fashion. An entropy close to zero reflects the average ("normal") affiliation change behavior. Each historical affiliation change contributes to the aggregate measure of entropy. If a past affiliation survives for less than 13 years (the industry average), its entropy contribution is positive (i.e., higher disarray than normal). However, if the same property enjoyed another affiliation for a much larger time period ( $>13$ years), it could help make up for the disarray by contributing negatively to the entropy measure. Besides, recent affiliation changes will have a stronger weight in the entropy measure compared with the earlier ones. In short, a positive entropy reflects abnormally high perceived changes to affiliation in the past. Similarly, a negative entropy reflects abnormally low perceived changes to affiliation in the past.

\section{Method}

First, we apply a nonparametric survival function to our sample. In particular, we identify the event of affiliation change as a "hazard." A hotel not faced with this hazard at a certain age is supposed to have "survived" until that age. As a result, survival is conditional on a hotel's not having met with a hazard until then. However, many hotel brands, which seem to have survived until the date of our observation, may eventually meet with a hazard in the future and may bias our estimated survival duration. Such observations are termed censored. A hotel might encounter multiple hazards (i.e., it may change its brand affiliation many times). We focus on the most recently observed hazard primarily because we have the best quality of data related to a hotel's attributes for its most recent hazard. Our ENTROPY measure incorporates a rich set of past hazard information. Moreover, in the latter part of our study, we also incorporate the information about earlier affiliation changes.

Survival functions have been applied in several earlier studies in other contexts, such as firm takeovers (Malmendier et al., 2016), turnover of CEOs (Jenter \& Kanaan, 2015), modification to equity stakes (Bradley et al., 2016), and survival of loans (Ambrose et al., 2016; Chen \& Deng, 2013; Das $\&$ Freybote, in press; Liu \& Sing, 2017). For hotels that never changed their affiliation, we record the hazard $(=0)$ during the last time period of our data collection (i.e., December 2017).

Suppose the survival function $S(t)$ is the probability that a hotel retained its current affiliation until its age $t$, and $T$ is the age at which the hazard (i.e., affiliation change) takes place. $F(t)=\mathrm{P}(\mathrm{T}<t)$ is the hazard function ${ }^{16}$ denoting the probability that the hazard has occurred by age $t$, and $f(t)$ is the probability that the hazard occurs at age $t$ :

$$
S(t)=P(T \geq t)=1-F(t)=\int_{t}^{\infty} f(x) d x .
$$




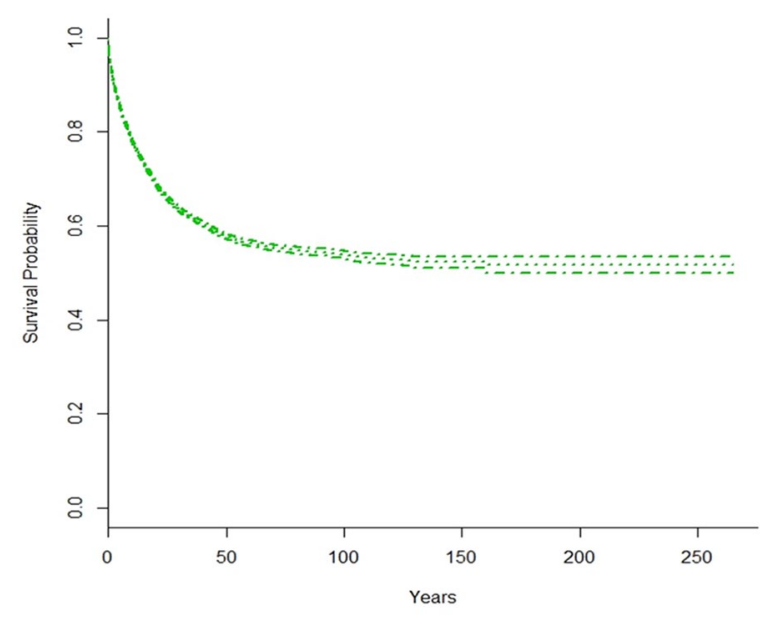

Figure 2.

Kaplan-Meier Survival Function for Hotel Brand Affiliations in the United States.

Source. Data provided by STR Global.

Note. The survival function is based on a sample of 48,300 hotel properties recorded in the United States between 1990 and 2017. The $\mathrm{X}$-axis depicts the property age. The $\mathrm{Y}$-axis depicts the probability of survival of the most recent brand.

Given the condition that an affiliation survived until the hotel age $t$, the baseline hazard rate is,

$$
h_{0}(t)=\frac{f(t)}{S(t)} .
$$

Applying the Cox Proportional Hazard (CPH) model, we can explain the hazard function using covariates $(X)$ beyond the hotel age $(t)$ :

$$
h(t \mid X)=h_{0}(t) e^{\beta X} .
$$

In such a modeling framework, the hazard rate across two hotels (say, $p$ and $q$ ) across different ages $(t)$ will maintain the same ratio, that is, $h_{p}(t) / h_{q}(t)$ is a constant.

\section{Results and Discussion}

\section{Baseline Survival Curves}

The Kaplan-Meier Survival curves are shown in Figures 2 through 4 . The $\mathrm{X}$-axis in these graphs depicts how long the most recent affiliation has survived. The Y-axis provides the corresponding probability of surviving that duration.

The survival probability of a brand affiliation drops steeply in the first 50 years, after which it tends to plateau. The confidence intervals are narrowly spaced in early years and gradually widen over time. In Figure 3, we split the curve across subsamples based on hotel location type. Hotel brand affiliations in small metros or towns survive the longest whereas the brand survival in transit-oriented hotels

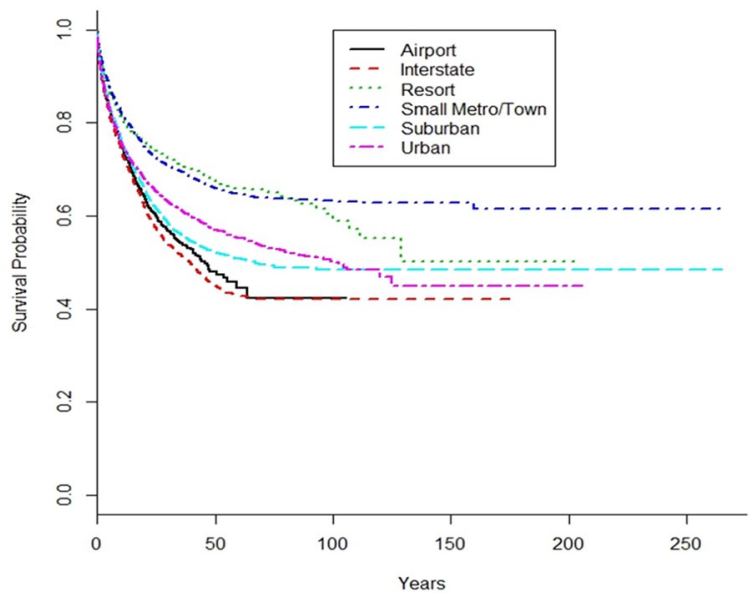

Figure 3.

Kaplan-Meier Survival Function for Hotel Brand Affiliations in the United States by Location Type. Source. Data provided by STR Global.

Note. The survival function is based on a sample of 48,300 hotel properties recorded in the United States between 1990 and 2017. The $\mathrm{X}$-axis depicts the property age. The $\mathrm{Y}$-axis depicts the probability of survival of the most recent brand.

(airport, interstate highways) falls steeper with age compared with other types. Suburban hotels show a somewhat similar trend, although their conditional brand survival probability improves after 50 years of survival.

Hotels of different classes exhibit different brand survival patterns, as shown in Figure 4. Independent hotels exhibit significantly superior resilience in retaining their identity over their lives. Brand affiliation in superior class (luxury, upper upscale) hotels survives longer compared with lower class hotels. ${ }^{17}$ We also note differing survival patterns across geographic regions (see Figure 5). Brand survival is the highest in the Northeast-Central region (New York, Pennsylvania, New Jersey) and lowest in the Southwest (Texas, Louisiana, etc.), and the East NorthCentral region (Michigan, Illinois, Wisconsin, etc.) lies roughly at the median. Although insightful, the KaplanMeier survival curve is nonparametric in nature. Besides, several other factors not depicted in the curves may confound a brand's survival.

\section{Proportional Hazard Models}

To study the factors associated with the decision of a property to change affiliation or business model, we use three different sets of models. In the first set, we analyze how a property's attributes and market factors determine a hotel's propensity to rebrand (Table 2). In the second set of models, we focus on the type of change: We specifically study the choice to switch from a brand to another, to go from a brand to independent status, or from independent status to a brand 


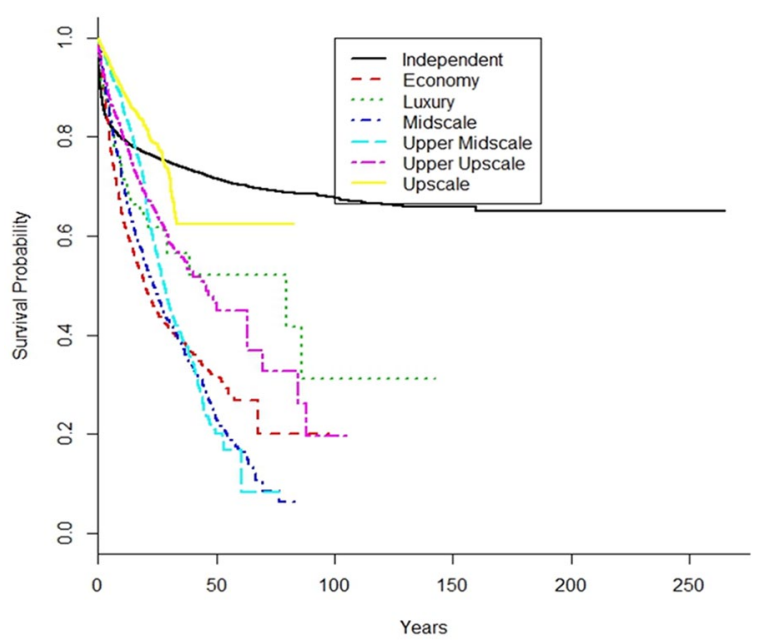

Figure 4.

Kaplan-Meier Survival Function for Hotel Brand Affiliations in the United States by Hotel Class. Source. Data provided by STR Global.

Note. The survival function is based on a sample of 48,300 hotel properties recorded in the United States between 1990 and 2017. The $\mathrm{X}$-axis depicts the property age. The $\mathrm{Y}$-axis depicts the probability of survival of the most recent brand.

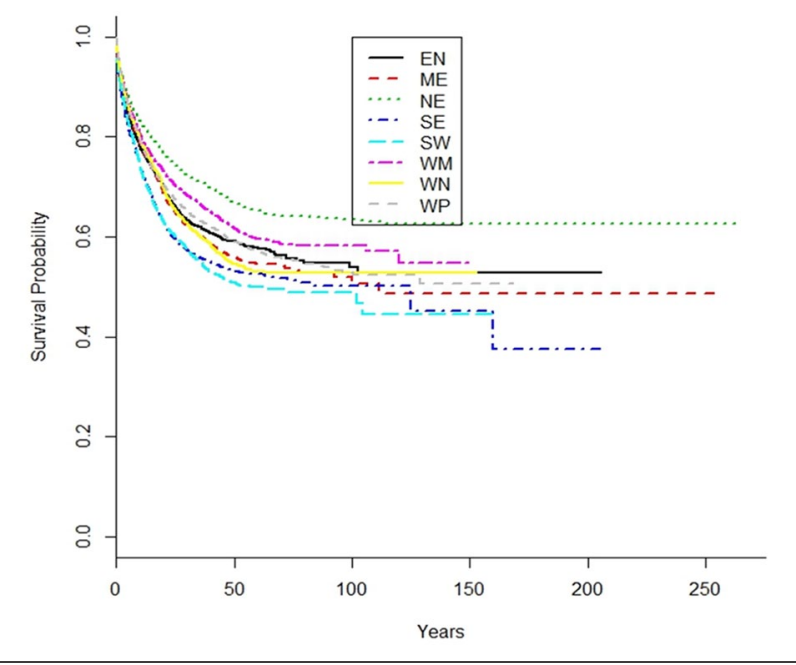

\section{Figure 5.}

Kaplan-Meier Survival Function for Hotel Brand Affiliations in the United States by Region. Source. Data provided by STR Global.

Note. The survival function is based on a sample of 48,300 hotel properties recorded in the United States between 1990 and 2017. The $\mathrm{X}$-axis depicts the property age. The $\mathrm{Y}$-axis depicts the probability of survival of the most recent brand. EN = East North-Central; ME = Mid-East; NE = Northeast; SE = Southeast; SW = Southwest; WM = Mountain; WN = West North-Central; WP = Pacific.

(see Table 3). Finally, we emphasize the differences across market segments to analyze the factors that lead to upscaling or downscaling (Table 4).
In the first set of models, we analyze how property attributes, broad financial markets, and trends in respective hotel markets affect the rebranding propensity. The results are presented in Table 2. Due to unobserved variables, a hotel's historical record of brand changes may also be associated with its propensity to change in the future. We control for the past record in our models in two different ways. First, we control for the number of affiliation changes observed before the most recent one (NX). In the second specification (2), we replace the number of past changes (NX) by ENTROPY. In the last specification (3), we add some interaction terms between financial variables.

We show that NX and ENTROPY display a nonlinear relationship with rebranding. Indeed, the number of past switches positively affects the likelihood of future changes, up to a point, after which the likelihood of future changes goes down with an increase in these variables. In particular, we observe that up to two past changes,${ }^{18}$ each change adds to the propensity of future rebranding. However, the association reverts to negative for a larger number of rebrandings in the past. Thus, if a hotel has already witnessed two affiliation changes, each additional change will diminish its tendency to change again in the future. We find a similar association when NX is replaced by ENTROPY. Up to a certain extent (i.e., ENTROPY = 2.17), the historical disarray in rebranding positively affects the future change, after which the association turns negative. ${ }^{19}$ A hotel may hit this threshold ENTROPY in several ways (e.g., having changed their brand too quickly, up to 3 times in the past 5 years). This finding suggests that if a certain number of affiliation changes can give an idea of dynamism, too many changes might end up signaling an inherent instability. The (pseudo) $R^{2}$ associated to the two specifications are equivalent, thus, indicating that we can use those two indicators interchangeably, although ENTROPY has superior information content. As Table 2 shows, some determinants are consistent in their association with rebranding across the three specifications. For example, the property age is significant and negative across all specifications: The older the property at the time of its last affiliation change, the less likely will future brand changes be observed. In other words, newer hotels have a stronger tendency to rebrand.

STR's "scale" classification distinguishes between independent hotels and six classes of chains (luxury, upper upscale, upscale, upper midscale, and economy). We observe that chains operating in all market segments are more likely than independent hotels to rebrand. Note, however, that the coefficient associated with upscale hotels is consistently insignificant across the three specifications. In the three specifications, we observe that the probability of rebranding for upper midscale and upper upscale hotels is relatively low. Hotels with a larger number of rooms and floors are more likely to change affiliation. We also analyzed hotels by location and in relative terms with respect to airport hotels. Interstate hotels are relatively more likely to 
Table 2.

Cox Proportional Hazard Models of Affiliation Change.

\begin{tabular}{|c|c|c|c|}
\hline \multirow[b]{3}{*}{ Variable } & \multicolumn{3}{|c|}{ Full Sample } \\
\hline & Baseline-I & Baseline-2 & With VIX Interactions \\
\hline & (I) & (2) & (3) \\
\hline NX & $\begin{array}{l}1.440 * * * \\
(0.028)\end{array}$ & & \\
\hline ENTROPY ${ }^{2}$ & $\begin{array}{c}-0.326 * * * \\
(0.009)\end{array}$ & & \\
\hline ENTROPY & & $\begin{array}{l}0.597 * * * \\
(0.013)\end{array}$ & $\begin{array}{l}0.597 \text { *** } \\
(0.013)\end{array}$ \\
\hline ENTROPY ${ }^{2}$ & & $\begin{array}{l}-0.137^{* * *} \\
(0.005)\end{array}$ & $\begin{array}{l}-0.137^{* * * *} \\
(0.005)\end{array}$ \\
\hline AGE & $\begin{array}{l}-0.050^{* * *} \\
(0.001)\end{array}$ & $\begin{array}{l}-0.025^{* * *} \\
(0.001)\end{array}$ & $\begin{array}{c}-0.025^{* * *} \\
(0.001)\end{array}$ \\
\hline Economy & $\begin{array}{l}0.176 * * * \\
(0.023)\end{array}$ & $\begin{array}{l}0.208 * * * \\
(0.023)\end{array}$ & $\begin{array}{l}0.207^{* * *} \\
(0.023)\end{array}$ \\
\hline Luxury & $\begin{array}{l}0.346 * * * \\
(0.113)\end{array}$ & $\begin{array}{c}0.192 * \\
(0.113)\end{array}$ & $\begin{array}{c}0.198^{*} \\
(0.113)\end{array}$ \\
\hline Midscale & $\begin{array}{l}0.203 * * * \\
(0.028)\end{array}$ & $\begin{array}{l}0.174^{* * *} \\
(0.028)\end{array}$ & $\begin{array}{l}0.168^{* * *} \\
(0.028)\end{array}$ \\
\hline Upper Midscale & $\begin{array}{l}0.121^{* * *} \\
(0.029)\end{array}$ & $\begin{array}{c}0.063^{* *} \\
(0.029)\end{array}$ & $\begin{array}{c}0.06 I^{* *} \\
(0.029)\end{array}$ \\
\hline Upper Upscale & $\begin{array}{l}0.143 * * \\
(0.059)\end{array}$ & $\begin{array}{l}0.125^{* *} \\
(0.059)\end{array}$ & $\begin{array}{c}0.122^{* *} \\
(0.059)\end{array}$ \\
\hline Upscale & $\begin{array}{c}-0.063 \\
(0.053)\end{array}$ & $\begin{array}{c}0.061 \\
(0.053)\end{array}$ & $\begin{array}{c}0.059 \\
(0.053)\end{array}$ \\
\hline ROOMS & $\begin{array}{l}0.001 * * * \\
(0.0001)\end{array}$ & $\begin{array}{l}0.00 I^{* * *} \\
(0.000 \mathrm{I})\end{array}$ & $\begin{array}{l}0.00 \mathrm{I} * * * \\
(0.000 \mathrm{I})\end{array}$ \\
\hline FLOORS & $\begin{array}{l}0.014 * * * \\
(0.004)\end{array}$ & $\begin{array}{l}0.013^{* * *} \\
(0.004)\end{array}$ & $\begin{array}{l}0.013^{* * *} \\
(0.004)\end{array}$ \\
\hline Interstate & $\begin{array}{l}0.154 * * * \\
(0.050)\end{array}$ & $\begin{array}{l}0.154^{* * *} \\
(0.050)\end{array}$ & $\begin{array}{l}0.157^{* * *} \\
(0.050)\end{array}$ \\
\hline Resort & $\begin{array}{c}-0.087 \\
(0.058)\end{array}$ & $\begin{array}{c}-0.093 \\
(0.058)\end{array}$ & $\begin{array}{c}-0.095^{*} \\
(0.058)\end{array}$ \\
\hline Small Metro/Town & $\begin{array}{c}0.072 \\
(0.049)\end{array}$ & $\begin{array}{c}0.032 \\
(0.049)\end{array}$ & $\begin{array}{c}0.033 \\
(0.049)\end{array}$ \\
\hline Suburban & $\begin{array}{c}0.040 \\
(0.043)\end{array}$ & $\begin{array}{c}0.029 \\
(0.043)\end{array}$ & $\begin{array}{c}0.030 \\
(0.043)\end{array}$ \\
\hline Urban & $\begin{array}{c}-0.058 \\
(0.050)\end{array}$ & $\begin{array}{c}-0.056 \\
(0.050)\end{array}$ & $\begin{array}{c}-0.056 \\
(0.050)\end{array}$ \\
\hline CONVENTION & $\begin{array}{c}-0.060 \\
(0.078)\end{array}$ & $\begin{array}{c}-0.072 \\
(0.078)\end{array}$ & $\begin{array}{c}-0.072 \\
(0.078)\end{array}$ \\
\hline BOUTIQUE & $\begin{array}{l}0.688 * * * \\
(0.058)\end{array}$ & $\begin{array}{l}0.609 * * * \\
(0.058)\end{array}$ & $\begin{array}{l}0.611^{* * *} \\
(0.058)\end{array}$ \\
\hline ALLSUITE & $\begin{array}{c}-0.033 \\
(0.033)\end{array}$ & $\begin{array}{l}-0.162^{* * * *} \\
(0.033)\end{array}$ & $\begin{array}{c}-0.161 * * * \\
(0.033)\end{array}$ \\
\hline MKT & $\begin{array}{c}0.003^{*} \\
(0.002)\end{array}$ & $\begin{array}{c}0.003^{*} \\
(0.002)\end{array}$ & $\begin{array}{l}0.004^{* *} \\
(0.002)\end{array}$ \\
\hline TERM & $\begin{array}{l}0.225 * * * \\
(0.031)\end{array}$ & $\begin{array}{l}0.226 \text { *** } \\
(0.031)\end{array}$ & $\begin{array}{l}0.230 * * * \\
(0.032)\end{array}$ \\
\hline VIX & $\begin{array}{l}0.022 * * * \\
(0.003)\end{array}$ & $\begin{array}{l}0.024 * * * \\
(0.003)\end{array}$ & $\begin{array}{l}0.024 * * * \\
(0.004)\end{array}$ \\
\hline
\end{tabular}


Table 2. (continued)

\begin{tabular}{|c|c|c|c|}
\hline \multirow[b]{3}{*}{ Variable } & \multicolumn{3}{|c|}{ Full Sample } \\
\hline & Baseline-I & Baseline-2 & With VIX Interactions \\
\hline & (I) & $(2)$ & (3) \\
\hline \multirow[t]{2}{*}{ NPI } & $0.052 * * *$ & $0.060 * * *$ & $0.095^{* * *}$ \\
\hline & $(0.015)$ & $(0.015)$ & $(0.017)$ \\
\hline \multirow[t]{2}{*}{ IR } & $3.85 \mathrm{I} * * *$ & $4.266 * * *$ & $7.813^{* *}$ \\
\hline & $(1.204)$ & $(1.197)$ & $(3.335)$ \\
\hline \multirow[t]{2}{*}{$A R$} & $1.740 * * *$ & $1.832^{* * * *}$ & $3.909 * * *$ \\
\hline & $(0.370)$ & $(0.368)$ & $(0.663)$ \\
\hline \multirow[t]{2}{*}{$\mathrm{VIX} \times \quad \mathrm{IR}$} & & & -0.190 \\
\hline & & & $(0.162)$ \\
\hline \multirow[t]{2}{*}{$\mathrm{VIX} \times \mathrm{AR}$} & & & $-0.093 * * *$ \\
\hline & & & $(0.025)$ \\
\hline Monthly Seasonality & Yes & Yes & Yes \\
\hline Annual Trend & Yes & Yes & Yes \\
\hline NCREIF Region & Yes & Yes & Yes \\
\hline Metro Markets & Yes & Yes & Yes \\
\hline$N$ & 43,041 & 43,041 & 43,041 \\
\hline$R^{2}$ & .548 & .521 & .521 \\
\hline Max. Possible $R^{2}$ & .998 & .998 & .998 \\
\hline Log Likelihood & $-122,778.400$ & $-124,006.700$ & $-123,998.400$ \\
\hline Wald Test & $19,040.880 * * *(d f=23 \mathrm{I})$ & $17,448.540 * * *(d f=23 \mathrm{I})$ & $17,465.720 * * *(d f=233)$ \\
\hline Logrank Test & $34, \mid 50.880 * * *(d f=23 \mathrm{I})$ & $31,694.200 * * *(d f=23 \mathrm{I})$ & $31,710.790 * * *(d f=233)$ \\
\hline Score (Logrank) & $37,659.4 \mathrm{I} 0 * * *(d f=23 \mathrm{I})$ & $37,667.150 * * *(d f=23 \mathrm{I})$ & $37,688.970 * * *(d f=233)$ \\
\hline Test & & & \\
\hline
\end{tabular}

Note. This table presents the regression coefficients for Cox Proportional Hazard model applied to a sample of hotels between 1990 and 2017. Change in hotel's affiliation is the hazard. Quantities in the parentheses signify the standard errors unless specified otherwise. ROOMS = Number of rooms; FLOORS = number of floors. The following dummy variables signify the respective hotel types or amenities provided: RESTAURANT, CONVENTION, SPA, BOUTIQUE, ALLSUITE. The following dummy variables signify the location type of a hotel: Airport (reference group), Interstate, Resort, Small Metro/Town, Suburban, Urban; NX = Number of times a hotel changed its affiliation before the most recent change during the sample period; ENTROPY = a historical measure of a hotel's affiliation stability weighted by recency; AGE $=$ age of a hotel (in years) at the time of its affiliation change; EXSCALE = dummy variable for the previous scale from which the affiliation changed (reference group: Independent); NCREIFREGION = dummy variable for regional classification: EN = East North-Central: reference group; ME = Mid-East; NE = Northeast; SE = Southeast; SW = Southwest; WM = Mountain; WN = West North-Central; WP = Pacific. The following variables refer to the regional-level hotel returns data corresponding to the quarter when a hotel changed affiliation: NPI = NCREIF commercial property index; IR = income return; $A R=$ appreciation return. The following data refer to the national level financial/real estate indices corresponding to the quarter when a hotel changed affiliation: MKT = Return on the Standard \& Poor's (S\&P) 500 Index in excess of the risk-free rate; TERM = Yield spread between I0-Year Treasury Bond and the risk-free rate; DEFAULT = Yield spread between Moody's BAA -rated Corporate bonds and the risk-free rate; VIX = Chicago Board Options Exchange [CBOE]'s Option-pricing-based Volatility Index for the Stock Market; NPI = Return on NCREIF Commercial Property Index. The Risk-free rate is defined as the yield on 3-Month Treasury Bill. NCREIF = National Council of Real Estate Investment Fiduciaries. ***, **, and $*$ signify statistical significance at $1 \%, 5 \%$, and $10 \%$ levels, respectively.

change brand, while there is no significant difference between all the other locations and airport hotels. Intuitively, the high visibility of interstate hotels makes them more dynamic than all the other categories of hotels.

Boutique hotels are associated with a highly significant and positive rebranding hazard, while the association is insignificant for all-suite hotels in the first specification (1) and negative in the other two (2 and 3). Boutique hotels are more flexible in their business model. All-suite hotels may, instead, be dominated by corporate clients and are less likely to change affiliation because they must maintain the positioning. Besides, due to their atypicality (Blal \& Graf,
2013), there are fewer brand options for all-suite hotels to choose from.

The last fundamental factor in our analysis is financial performance. In this section, we include measures of market performance and volatility, as well as indicators that are more specific to the real estate and hotel industries. Stock market performance (MKT), represented by excess return on the Standard \& Poor's (S\&P) 500 index, is only weakly significant, indicating that affiliation changes are not strongly associated with the overall stock market. Stock market returns reflect the current market conditions. Due to a high degree of market efficiency, they do not offer useful 
Table 3.

Cox Proportional Hazard Models of Various Types of Affiliation Change.

\begin{tabular}{|c|c|c|c|c|}
\hline \multirow[b]{3}{*}{ Variable } & \multicolumn{4}{|c|}{ Subsamples } \\
\hline & Independent to Brand & Brand to Independent & Brand to Brand & Same Brand Parent \\
\hline & (I) & $(2)$ & (3) & (4) \\
\hline \multirow[t]{2}{*}{ ENTROPY } & $0.450 * * *$ & $0.633 * * *$ & $0.674 * * *$ & $0.611 * * *$ \\
\hline & $(0.023)$ & $(0.028)$ & $(0.022)$ & $(0.035)$ \\
\hline \multirow{2}{*}{ ENTROPY $^{2}$} & $-0.125 * * *$ & $-0.115 * * *$ & $-0.156 * * *$ & $-0.154 * * *$ \\
\hline & $(0.008)$ & $(0.010)$ & $(0.008)$ & $(0.014)$ \\
\hline \multirow[t]{2}{*}{ AGE } & $-0.039 * * *$ & $0.005^{* * *}$ & $-0.027 * * *$ & $0.008 * * *$ \\
\hline & $(0.00 \mathrm{I})$ & $(0.002)$ & $(0.001)$ & $(0.002)$ \\
\hline \multirow[t]{2}{*}{ Economy } & -20.388 & 20.060 & $2.235^{* * *}$ & $0.679 * * *$ \\
\hline & $(419.113)$ & $(304.108)$ & $(0.058)$ & $(0.078)$ \\
\hline \multirow[t]{2}{*}{ Luxury } & -19.126 & 19.252 & $2.419 * * *$ & $1.570 * * *$ \\
\hline & $(1,479.620)$ & $(304.108)$ & $(0.152)$ & $(0.215)$ \\
\hline \multirow[t]{2}{*}{ Midscale } & $-20.4 \mid 4$ & 19.725 & $2.425 * * *$ & $0.721 * * *$ \\
\hline & $(540.754)$ & $(304.108)$ & $(0.060)$ & $(0.092)$ \\
\hline \multirow[t]{2}{*}{ Upper Midscale } & -20.126 & 19.190 & $2.507 * * *$ & I.749*** \\
\hline & $(463.288)$ & $(304.108)$ & $(0.060)$ & $(0.074)$ \\
\hline \multirow[t]{2}{*}{ Upper Upscale } & -19.778 & 19.666 & $2.331 * * *$ & $1.867 * * *$ \\
\hline & $(981.901)$ & $(304.108)$ & $(0.089)$ & $(0.125)$ \\
\hline \multirow[t]{2}{*}{ Upscale } & $-|9.65|$ & 19.503 & $2.358 * * *$ & $1.026 * * *$ \\
\hline & $(792.240)$ & $(304.108)$ & $(0.08 \mathrm{I})$ & $(0.143)$ \\
\hline \multirow[t]{2}{*}{ ROOMS } & $0.00 I^{* * *} *$ & 0.0001 & $0.0003^{*}$ & -0.0004 \\
\hline & $(0.0002)$ & $(0.0003)$ & $(0.0002)$ & $(0.0003)$ \\
\hline \multirow[t]{2}{*}{ FLOORS } & $0.013^{* *}$ & $-0.034 * * *$ & $0.023 * * *$ & $0.021 * *$ \\
\hline & $(0.005)$ & $(0.010)$ & $(0.005)$ & $(0.008)$ \\
\hline \multirow[t]{2}{*}{ Interstate } & 0.026 & $0.286 * *$ & $0.129 *$ & 0.098 \\
\hline & $(0.100)$ & $(0.116)$ & $(0.069)$ & $(0.14 I)$ \\
\hline \multirow[t]{2}{*}{ Resort } & $-0.677 * * *$ & $0.824 * * *$ & -0.063 & $0.427 * * *$ \\
\hline & $(0.114)$ & $(0.124)$ & $(0.085)$ & $(0.15 I)$ \\
\hline \multirow[t]{2}{*}{ Small Metro/Town } & $-0.436 * * *$ & $0.718^{* * * *}$ & -0.003 & 0.188 \\
\hline & $(0.099)$ & $(0.1 \mid 3)$ & $(0.069)$ & $(0.137)$ \\
\hline \multirow[t]{2}{*}{ Suburban } & -0.106 & $0.173 *$ & 0.027 & 0.068 \\
\hline & $(0.091)$ & $(0.102)$ & $(0.057)$ & $(0.118)$ \\
\hline \multirow[t]{2}{*}{ Urban } & $-0.385 * * *$ & $0.407 * * *$ & -0.101 & -0.134 \\
\hline & $(0.101)$ & $(0.1 \mid 4)$ & $(0.069)$ & $(0.134)$ \\
\hline \multirow[t]{2}{*}{ CONVENTION } & $-0.232 *$ & 0.030 & 0.045 & 0.020 \\
\hline & $(0.140)$ & $(0.193)$ & $(0.1 I I)$ & $(0.190)$ \\
\hline \multirow[t]{2}{*}{ BOUTIQUE } & 0.029 & $1.337 * * *$ & $0.955^{* * *}$ & $1.205^{* * *}$ \\
\hline & $(0.090)$ & $(0.140)$ & $(0.099)$ & $(0.123)$ \\
\hline \multirow[t]{2}{*}{ ALLSUITE } & $-0.521 * * *$ & -0.082 & $0.189 * * *$ & 0.137 \\
\hline & $(0.068)$ & $(0.082)$ & $(0.044)$ & $(0.090)$ \\
\hline \multirow[t]{2}{*}{ MKT } & $0.008^{*}$ & -0.0002 & $0.008 * * *$ & 0.005 \\
\hline & $(0.004)$ & $(0.004)$ & $(0.003)$ & $(0.007)$ \\
\hline TERM & $0.296 * * *$ & 0.090 & $0.220 * * *$ & 0.010 \\
\hline & $(0.058)$ & $(0.065)$ & $(0.047)$ & $(0.088)$ \\
\hline VIX & $0.040 * * *$ & $0.024 * * *$ & 0.007 & $0.037 * * *$ \\
\hline & $(0.008)$ & $(0.009)$ & $(0.006)$ & $(0.0 \mid 2)$ \\
\hline NPI & $0.110 * * *$ & 0.027 & $0.077 * * *$ & $0.096 * *$ \\
\hline & $(0.032)$ & $(0.036)$ & $(0.026)$ & $(0.048)$ \\
\hline IR & $15.193^{* *}$ & -0.433 & 5.317 & 9.136 \\
\hline
\end{tabular}


Table 3. (continued)

\begin{tabular}{|c|c|c|c|c|}
\hline \multirow[b]{3}{*}{ Variable } & \multicolumn{4}{|c|}{ Subsamples } \\
\hline & Independent to Brand & Brand to Independent & Brand to Brand & Same Brand Parent \\
\hline & (I) & $(2)$ & (3) & (4) \\
\hline & $(6.293)$ & $(6.743)$ & $(4.977)$ & $(8.458)$ \\
\hline \multirow[t]{2}{*}{ AR } & $4.591 * * *$ & 2.221 & $5.311 * * *$ & 0.510 \\
\hline & $(1.220)$ & $(1.428)$ & $(0.963)$ & $(1.869)$ \\
\hline \multirow[t]{2}{*}{$\mathrm{VIX} \times \mathrm{AR}$} & $-0.090 * *$ & 0.004 & $-0.157 * * *$ & 0.003 \\
\hline & $(0.045)$ & $(0.055)$ & $(0.036)$ & $(0.067)$ \\
\hline \multirow[t]{2}{*}{$\mathrm{VIX} \times \mathrm{IR}$} & $-0.54 I^{*}$ & 0.057 & -0.058 & -0.187 \\
\hline & $(0.298)$ & $(0.325)$ & $(0.247)$ & $(0.394)$ \\
\hline Monthly Seasonality & Yes & Yes & Yes & Yes \\
\hline Annual Trend & Yes & Yes & Yes & Yes \\
\hline NCREIF Region & Yes & Yes & Yes & Yes \\
\hline Metro Markets & Yes & Yes & Yes & Yes \\
\hline$N$ & 43,041 & 43,041 & 43,041 & 43,041 \\
\hline$R^{2}$ & .347 & .242 & .372 & .107 \\
\hline Max. Possible $R^{2}$ & .872 & .773 & .948 & .563 \\
\hline Log Likelihood & $-35,000.950$ & $-25,997.240$ & $-53,726.540$ & $-15,389.55$ \\
\hline Wald Test $(d f=233)$ & $4,500.420 * * *$ & $4,361.790 * * *$ & $9,870.740 * * *$ & $3,352.030 * * *$ \\
\hline Logrank Test $(d f=233)$ & $18,374.640 * * *$ & $11,901.910^{* * *}$ & $19,993.520 * * *$ & $4,871.673 * * *$ \\
\hline Score (Logrank) Test $(d f=233)$ & $21,417.220 * * *$ & $14,399.060 * * *$ & $22,410.140 * * *$ & $6,533.241 * * *$ \\
\hline
\end{tabular}

Note. This table presents the regression coefficients for Cox Proportional Hazard model applied to a sample of hotels between 1990 and 2017. Change in hotel's affiliation is the hazard. Quantities in the parentheses signify the standard errors unless specified otherwise. ROOMS = number of rooms; FLOORS = number of floors. The following dummy variables signify the respective hotel types or amenities provided: RESTAURANT, CONVENTION, SPA, BOUTIQUE, ALLSUITE. The following dummy variables signify the location type of a hotel: Airport (reference group), Interstate, Resort, Small Metro/Town, Suburban, Urban; NX = number of times a hotel changed its affiliation before the most recent change during the sample period; ENTROPY = a historical measure of a hotel's affiliation stability weighted by recency; AGE = age of a hotel (in years) at the time of its affiliation change; EXSCALE = dummy variable for the previous scale from which the affiliation changed (reference group: Independent); NCREIFREGION = dummy variable for regional classification: EN = East North-Central: reference group; ME = Mid-East; NE = Northeast; SE = Southeast; $S W=$ Southwest; WM = Mountain; WN = West North-Central; WP = Pacific. The following variables refer to the regional-level hotel returns data corresponding to the quarter when a hotel changed affiliation: NPI = NCREIF Commercial Property Index; IR = income return; AR $=$ appreciation return. The following data refer to the national level financial/real estate indices corresponding to the quarter when a hotel changed affiliation: MKT = Return on the Standard and Poor's (S\&P) 500 Index in excess of the risk-free rate; TERM = Yield spread between I0-Year Treasury Bond and the risk-free rate; DEFAULT = Yield spread between Moody's BAA-rated Corporate bonds and the risk-free rate; VIX = Chicago Board Options Exchange [CBOE]'s Option-pricing-based Volatility Index for the Stock Market; NPI = Return on NCREIF Commercial Property Index. The Risk-free rate is defined as the yield on 3-Month Treasury Bill; NCREIF = National Council of Real Estate Investment Fiduciaries.

$* * *, * *$, and $*$ signify statistical significance at $1 \%, 5 \%$, and $10 \%$ levels, respectively.

signals for the market conditions in the medium or long term. Nevertheless, the slope of the yield curve (TERM) positively affects the likelihood of brand change. The term spread is reflective of an expected future expansion of the economy. We observe that a better performance in the real estate industry, ${ }^{20}$ also, is associated with a higher hazard rate. Finally, specific to the hotel industry, a higher IR and AR generated by hotels increases the propensity to rebrand. Hotel and real estate industries are known for their inefficiency. As a result, returns may persist longer and are reflective of the future outlook. Rebranding is a strategic decision for hotels, given the long average survival/contractual time of the affiliations. Therefore, it is intuitive that the decisions are based on the future outlook of the market. In general, improving market conditions increase the rebranding propensity. More specifically, positive returns on commercial properties and hotels increase the contractual power of hotels that go on the market and sign new contracts. Higher volatility in the stock market, measured by the VIX index, also increases the likelihood of brand change. Nevertheless, the interactions of uncertainty with $\mathrm{AR}$ and IR mitigates the individual positive effects of those two regressors.

\section{Types of Rebranding}

In Table 3, we look specifically at business model changes: changes from brand to independent or from independent to brand. In Table $1,10 \%$ of the hotels in our hazard sample are of independent-to-brand or brand-to-brand type each, 
Table 4.

Cox Proportional Hazard Models for Various Types of Scale Changes in Affiliation.

\begin{tabular}{|c|c|c|}
\hline \multirow[b]{3}{*}{ Variable } & \multicolumn{2}{|c|}{ Subsamples } \\
\hline & Upscaling & Downscaling \\
\hline & (I) & $(2)$ \\
\hline \multirow[t]{2}{*}{ ENTROPY } & $0.855^{* * *}$ & $0.836 * * *$ \\
\hline & $(0.048)$ & $(0.048)$ \\
\hline \multirow[t]{2}{*}{ ENTROPY ${ }^{2}$} & $-0.201 * * *$ & $-0.145 * * *$ \\
\hline & $(0.017)$ & $(0.017)$ \\
\hline \multirow[t]{2}{*}{ AGE } & $-0.063 * * *$ & $-0.055 * * *$ \\
\hline & $(0.003)$ & $(0.004)$ \\
\hline \multirow[t]{2}{*}{ Economy } & 19.797 & -0.355 \\
\hline & (574.372) & $(937.320)$ \\
\hline \multirow[t]{2}{*}{ Luxury } & -2.278 & 22.842 \\
\hline & $(6,593.782)$ & $(493.064)$ \\
\hline \multirow[t]{2}{*}{ Midscale } & 20.430 & 19.866 \\
\hline & (574.372) & (493.064) \\
\hline \multirow[t]{2}{*}{ Upper Midscale } & 19.048 & 20.820 \\
\hline & $(574.372)$ & $(493.064)$ \\
\hline \multirow[t]{2}{*}{ Upper Upscale } & 18.711 & 21.430 \\
\hline & (574.372) & $(493.064)$ \\
\hline \multirow[t]{2}{*}{ Upscale } & 19.197 & 21.251 \\
\hline & $(574.372)$ & $(493.064)$ \\
\hline \multirow[t]{2}{*}{ ROOMS } & $0.001 * * *$ & $-0.002 * * *$ \\
\hline & $(0.0003)$ & $(0.001)$ \\
\hline \multirow[t]{2}{*}{ FLOORS } & $0.080 * * *$ & $-0.107 * * *$ \\
\hline & $(0.009)$ & $(0.020)$ \\
\hline \multirow[t]{2}{*}{ Interstate } & $-0.404 * * *$ & $0.445 * * *$ \\
\hline & $(0.123)$ & $(0.147)$ \\
\hline \multirow[t]{2}{*}{ Resort } & $-0.511 * * *$ & $-0.489 * *$ \\
\hline & $(0.154)$ & $(0.202)$ \\
\hline \multirow[t]{2}{*}{ Small Metro/Town } & $-0.487 * * *$ & 0.216 \\
\hline & $(0.122)$ & $(0.15 \mathrm{I})$ \\
\hline \multirow[t]{2}{*}{ Suburban } & $-0.285 * * *$ & 0.103 \\
\hline & $(0.093)$ & $(0.129)$ \\
\hline \multirow[t]{2}{*}{ Urban } & -0.189 & $-0.417^{* *}$ \\
\hline & $(0.116)$ & $(0.172)$ \\
\hline \multirow[t]{2}{*}{ CONVENTION } & -0.010 & -0.036 \\
\hline & $(0.208)$ & $(0.287)$ \\
\hline \multirow[t]{2}{*}{ BOUTIQUE } & $1.546 * * *$ & $-0.728 *$ \\
\hline & $(0.193)$ & $(0.402)$ \\
\hline \multirow[t]{2}{*}{ ALLSUITE } & -0.054 & $-0.637 * * *$ \\
\hline & $(0.084)$ & $(0.116)$ \\
\hline \multirow[t]{2}{*}{ MKT } & 0.005 & $0.014 * *$ \\
\hline & $(0.005)$ & $(0.006)$ \\
\hline \multirow[t]{2}{*}{ TERM } & $0.207 * *$ & 0.113 \\
\hline & $(0.093)$ & $(0.097)$ \\
\hline VIX & -0.007 & $0.039 * * *$ \\
\hline & $(0.0 \mid 3)$ & $(0.0 \mid 4)$ \\
\hline NPI & $0.123 * *$ & 0.003 \\
\hline & $(0.053)$ & $(0.053)$ \\
\hline IR & -1.040 & $24.032^{* *}$ \\
\hline
\end{tabular}

(continued)
Table 4. (continued)

\begin{tabular}{|c|c|c|}
\hline \multirow[b]{3}{*}{ Variable } & \multicolumn{2}{|c|}{ Subsamples } \\
\hline & Upscaling & Downscaling \\
\hline & (I) & $(2)$ \\
\hline & $(10.357)$ & $(10.635)$ \\
\hline \multirow[t]{2}{*}{ AR } & $7.538 * * *$ & $6.152^{* * *}$ \\
\hline & $(1.772)$ & $(2.103)$ \\
\hline \multirow[t]{2}{*}{$\mathrm{VIX} \times \mathrm{AR}$} & $-0.248 * * *$ & -0.054 \\
\hline & $(0.064)$ & $(0.077)$ \\
\hline \multirow[t]{2}{*}{$\mathrm{VIX} \times \mathrm{IR}$} & 0.185 & $-1.138 * *$ \\
\hline & $(0.516)$ & $(0.532)$ \\
\hline Monthly Seasonality & Yes & Yes \\
\hline Annual Trend & Yes & Yes \\
\hline NCREIF Region & Yes & Yes \\
\hline Metro Markets & Yes & Yes \\
\hline$N$ & 43,041 & 43,041 \\
\hline$R^{2}$ & .180 & .186 \\
\hline Max. Possible $R^{2}$ & .572 & .515 \\
\hline Log Likelihood & $-13,972.370$ & $-11,144.110$ \\
\hline Wald Test $(d f=235)$ & $2,505.490 * * *$ & $2,309.130 * * *$ \\
\hline Logrank Test $(d f=235)$ & $8,546.458 * * *$ & $8,881.369 * * *$ \\
\hline $\begin{array}{l}\text { Score (Logrank) Test } \\
(d f=235)\end{array}$ & $11,118.310 * * *$ & $10,282.580 * * *$ \\
\hline
\end{tabular}

Note. This table presents the regression coefficients for Cox Proportional Hazard model applied to a sample of hotels between 1990 and 2017. Change in hotel's affiliation is the hazard. Quantities in the parentheses signify the standard errors unless specified otherwise. ROOMS = number of rooms; FLOORS = number of floors. The following dummy variables signify the respective hotel types or amenities provided: RESTAURANT, CONVENTION, SPA, BOUTIQUE, ALLSUITE. The following dummy variables signify the location type of a hotel: Airport (reference group), Interstate, Resort, Small Metro/Town, Suburban, Urban; NX = number of times a hotel changed its affiliation before the most recent change during the sample period; ENTROPY = a historical measure of a hotel's affiliation stability weighted by recency; $A G E=$ age of a hotel (in years) at the time of its affiliation change; EXSCALE = dummy variable for the previous scale from which the affiliation changed (reference group: Independent); NCREIFREGION = dummy variable for regional classification: EN = East North-Central: reference group; $M E=$ Mid-East; $N E=$ Northeast; $S E=$ Southeast; SW = Southwest; $\mathrm{WM}=$ Mountain; $\mathrm{WN}=$ West North-Central; $W P=$ Pacific. The following variables refer to the regional-level hotel returns data corresponding to the quarter when a hotel changed affiliation: NPI $=$ NCREIF Commercial Property Index; IR = income return; $A R=$ appreciation return. The following data refer to the national level financial/real estate indices corresponding to the quarter when a hotel changed affiliation: MKT = Return on the Standard \& Poor's (S\&P) 500 Index in excess of the risk-free rate; TERM = Yield spread between 10-Year Treasury Bond and the risk-free rate; DEFAULT $=$ Yield spread between Moody's BAA-rated Corporate bonds and the risk-free rate; VIX = Chicago Board Options Exchange [CBOE]'s Option-pricing-based Volatility Index for the Stock Market; NPI = Return on NCREIF Commercial Property Index. The Risk-free rate is defined as the yield on 3-Month Treasury Bill; NCREIF = National Council of Real Estate Investment Fiduciaries.

$* * *, * *$, and $*$ signify statistical significance at $1 \%, 5 \%$, and $10 \%$ levels, respectively. 
whereas $7 \%$ reflect changes from brand to independent, $15 \%$ from brand to brand, and $4 \%$ reflect changes within a brand. Most coefficients across these subsamples ${ }^{21}$ are broadly consistent with the models discussed in Table 2 . However, due to different rebranding types, the significance of the variables may vary. In this subsection, we identify the variables that are significantly different from each other across different types of rebranding.

Interestingly, the parameter associated with AGE switches its sign depending on the type of change considered. The sign is positive when we analyze changes from brand to independent or from brand to brand within the same parent company, while it is a negative sign when we consider changes from independent to brand or brand to brand across parent companies. The older the hotel at the time of its last change, the higher the probability either to become independent or to switch within the same parent company. The switch from brand to independent might indicate that the hotel has a consolidated management and reputation, which would explain the choice to operate without the help of a franchisor. Similarly, the same characteristic might strengthen the contractual power of the hotel within the same group, which might explain the decision to rebrand using that contractual advantage.

The probability of a radically changing business model is not significantly different for chains and independent hotels. In the case of interbrand changes, the probability of rebranding is similar across classes. Furthermore, upper classes appear to be particularly inclined to rebrand within the same parent company. These types of hotels cater to a specific customer segment that is sensitive to the brand identity. Therefore, it is intuitive for them to be less prone to giving up a parent affiliation. However, across the large chains, there is a wide range of luxury brands from which a hotel could choose.

Larger hotels (with more rooms) show a significantly higher propensity to change from independent to brand, and from brand to brand, while we do not find any significant difference between them and smaller hotels when we consider all the other rebranding strategies. Interestingly, hotels with a larger number of floors are relatively more inclined to go from independent to brand or from brand to brand, while they are less likely than hotels with a smaller number of floors to change from brand to independent. Resorts as well as small metro town and urban hotels are more likely than airport hotels to switch from brand to independent and less likely to go from independent to brand. The prestige of solid establishments like resorts gives them superior autonomy that reduces their need to be associated with a brand. Boutique hotels are more likely to change the business model and go from brand to independent or from brand to brand, especially within the same parent company. All-suite hotels exhibit a significantly smaller propensity to go from independent to brand, while they are significantly more prone to changing from one brand affiliation to another.

\section{Change in Scale}

Finally, in Table 4, we analyze the changes of scale associated with rebranding. In our sample, $4 \%$ of hotels upscaled their brand (e.g., economy to luxury) while changing the affiliation, and $4 \%$ downscaled. In this subsection, we report the determinants of the two types of affiliation changes. We do not find any significant difference in the propensity to downscale (upscale) between chains and independent hotels, as well as across classes. Hotels with a larger number of rooms are relatively more inclined to upscale than downscale. In addition, taller hotels (with more floors) are significantly more inclined to upscale and significantly less prone to downscale. Taller hotels enjoy superior recognition (Das et al., 2017), which may facilitate their upscaling. Interstate, small metro, suburban hotels, and resorts are significantly less likely to upscale than airport hotels. Interstate hotels are significantly more likely to downscale than airport hotels, while for resorts, we find the opposite. The likelihood of upscaling is higher for airport hotels than for all the other categories. Boutique and all-suite hotels are significantly less likely to downscale, while boutique hotels are significantly more likely to upscale.

The market performance positively affects the decision to downscale, while the spread between long-term and short-term bonds increases the likelihood of upscaling. Uncertainty increases the likelihood of downscaling, while it mitigates the incentives of upscaling when interacted with AR. The market return on commercial real estate, NPI, increases the incentives to upscale, while the regional average of income generated by hotels, IR, positively affects the propensity to downscale. The interaction between VIX and IR lowers the incentives to downscale. In general, we find that the interaction between uncertainty and other factors flips the sign of their individual effects. We could infer that higher uncertainty increases the perceived riskiness associated with a change in scale.

\section{Robustness Check}

In this section, we conduct some robustness tests to check the validity of our analysis. In Table 5, we test how our results change depending on the sample of hotels considered. In the first specification (1), we include the group of hotels that rebranded only once and all the ones that never changed. In the second specification (2), we only include those hotels that changed affiliation twice, plus the ones that never changed. In the last specification (3), we include all the hotels that changed at least 3 times (or more), plus all the ones that never changed.

The results are consistent with our baseline model results. Upscale chains, which were not significantly more likely than independent hotels to rebrand, now are associated with a 
Table 5.

Cox Proportional Hazard Models Across Number of Changes.

\begin{tabular}{|c|c|c|c|}
\hline \multirow[b]{3}{*}{ Variable } & \multicolumn{3}{|c|}{ Subsamples } \\
\hline & $\begin{array}{c}\text { First Change } \\
\text { Versus No Change }\end{array}$ & $\begin{array}{c}\text { Second Change Versus } \\
\text { No Change }\end{array}$ & $\begin{array}{l}\text { Third or Higher Change } \\
\text { Versus No Change }\end{array}$ \\
\hline & (I) & (2) & (3) \\
\hline \multirow[t]{2}{*}{ ENTROPY } & $1.103^{* * *}$ & $0.913^{* * *}$ & $0.739 * * *$ \\
\hline & $(0.023)$ & $(0.019)$ & $(0.020)$ \\
\hline \multirow[t]{2}{*}{ ENTROPY ${ }^{2}$} & $-0.318 * * *$ & $-0.191 * * *$ & $-0.111 * * *$ \\
\hline & $(0.016)$ & $(0.008)$ & $(0.007)$ \\
\hline \multirow[t]{2}{*}{ AGE } & $-0.035^{* * * *}$ & $-0.053^{* * *}$ & $-0.079 * * *$ \\
\hline & $(0.001)$ & $(0.001)$ & $(0.002)$ \\
\hline \multirow{2}{*}{ Economy } & $0.284 * * *$ & $0.518 * * *$ & $0.468 * * *$ \\
\hline & $(0.03 \mathrm{I})$ & $(0.035)$ & $(0.036)$ \\
\hline \multirow{2}{*}{ Luxury } & 0.218 & $0.465^{* * *}$ & 0.076 \\
\hline & $(0.148)$ & $(0.15 I)$ & $(0.182)$ \\
\hline \multirow[t]{2}{*}{ Midscale } & $0.206 * * *$ & $0.513 * * *$ & $0.567 * * *$ \\
\hline & $(0.035)$ & $(0.038)$ & $(0.040)$ \\
\hline \multirow[t]{2}{*}{ Upper Midscale } & $0.148 * * *$ & $0.435 * * *$ & $0.398 * * *$ \\
\hline & $(0.035)$ & $(0.039)$ & $(0.042)$ \\
\hline \multirow[t]{2}{*}{ Upper Upscale } & $0.156 * *$ & $0.462^{* * *}$ & $0.312^{* * *}$ \\
\hline & $(0.070)$ & $(0.078)$ & $(0.086)$ \\
\hline \multirow[t]{2}{*}{ Upscale } & $0.210^{* * *}$ & $0.390 * * *$ & $0.297^{* * * *}$ \\
\hline & $(0.066)$ & $(0.074)$ & $(0.083)$ \\
\hline \multirow[t]{2}{*}{ ROOMS } & $0.0004^{* * *}$ & $0.00 I^{* * *}$ & $0.001 * * *$ \\
\hline & $(0.000 \mathrm{I})$ & $(0.000 I)$ & $(0.000 \mathrm{I})$ \\
\hline \multirow[t]{2}{*}{ FLOORS } & $0.011 * *$ & $0.016 * * *$ & 0.005 \\
\hline & $(0.005)$ & $(0.005)$ & $(0.006)$ \\
\hline \multirow[t]{2}{*}{ Interstate } & $0.175^{* * *}$ & $0.168 * *$ & $0.131 *$ \\
\hline & $(0.062)$ & $(0.067)$ & $(0.069)$ \\
\hline \multirow[t]{2}{*}{ Resort } & -0.095 & -0.074 & $-0.209 * *$ \\
\hline & $(0.072)$ & $(0.078)$ & $(0.084)$ \\
\hline \multirow[t]{2}{*}{ Small Metro/Town } & 0.100 & 0.021 & 0.003 \\
\hline & $(0.062)$ & $(0.066)$ & $(0.069)$ \\
\hline \multirow[t]{2}{*}{ Suburban } & 0.077 & 0.030 & -0.052 \\
\hline & $(0.054)$ & $(0.058)$ & $(0.059)$ \\
\hline \multirow[t]{2}{*}{ Urban } & 0.054 & -0.104 & -0.045 \\
\hline & $(0.063)$ & $(0.067)$ & $(0.07 \mathrm{I})$ \\
\hline \multirow[t]{2}{*}{ CONVENTION } & -0.006 & 0.003 & -0.100 \\
\hline & $(0.100)$ & $(0.101)$ & $(0.119)$ \\
\hline \multirow[t]{2}{*}{ BOUTIQUE } & $0.612^{* * *}$ & $0.662^{* * *}$ & $0.526 * * *$ \\
\hline & $(0.073)$ & $(0.08 \mathrm{I})$ & $(0.094)$ \\
\hline \multirow[t]{2}{*}{ ALLSUITE } & $-0.068^{*}$ & $-0.155^{* * *}$ & $-0.172 * * *$ \\
\hline & $(0.037)$ & $(0.042)$ & $(0.043)$ \\
\hline \multirow[t]{2}{*}{ MKT } & 0.003 & 0.002 & 0.002 \\
\hline & $(0.002)$ & $(0.002)$ & $(0.002)$ \\
\hline TERM & $0.199 * * *$ & $0.313^{* * *}$ & $0.242^{* * *}$ \\
\hline & $(0.038)$ & $(0.043)$ & $(0.046)$ \\
\hline VIX & $0.024 * * *$ & $0.028 * * *$ & $0.020^{* * *}$ \\
\hline & $(0.005)$ & $(0.006)$ & $(0.006)$ \\
\hline NPI & $0.082 * * *$ & $0.105 * * *$ & $0.095 * * *$ \\
\hline & $(0.02 I)$ & $(0.023)$ & $(0.025)$ \\
\hline IR & 4.620 & $10.856 * *$ & 5.238 \\
\hline
\end{tabular}


Table 5. (continued)

\begin{tabular}{|c|c|c|c|}
\hline \multirow[b]{3}{*}{ Variable } & \multicolumn{3}{|c|}{ Subsamples } \\
\hline & $\begin{array}{c}\text { First Change } \\
\text { Versus No Change }\end{array}$ & $\begin{array}{c}\text { Second Change Versus } \\
\text { No Change }\end{array}$ & $\begin{array}{c}\text { Third or Higher Change } \\
\text { Versus No Change }\end{array}$ \\
\hline & (I) & $(2)$ & (3) \\
\hline & $(4.043)$ & $(4.475)$ & $(4.9 \mid 6)$ \\
\hline \multirow[t]{2}{*}{ AR } & $3.593^{* * *}$ & $2.883 * * *$ & $4.013^{* * *}$ \\
\hline & $(0.776)$ & $(0.853)$ & $(0.94 I)$ \\
\hline \multirow[t]{2}{*}{$\mathrm{VIX} \times \mathrm{AR}$} & $-0.080 * * *$ & $-0.088 * * *$ & $-0.100 * * *$ \\
\hline & $(0.030)$ & $(0.031)$ & $(0.037)$ \\
\hline \multirow[t]{2}{*}{$\mathrm{VIX} \times \mathrm{IR}$} & -0.235 & -0.324 & 0.054 \\
\hline & $(0.197)$ & $(0.217)$ & $(0.244)$ \\
\hline Monthly Seasonality & Yes & Yes & Yes \\
\hline Annual Trend & Yes & Yes & Yes \\
\hline NCREIF Region & Yes & Yes & Yes \\
\hline Metro Markets & Yes & Yes & Yes \\
\hline$N$ & 37,318 & 35,822 & 34,833 \\
\hline$R^{2}$ & .554 & .523 & .516 \\
\hline Max. Possible $R^{2}$ & .992 & .985 & .978 \\
\hline Log Likelihood & $-75,583.740$ & $-62,091.450$ & $-54,164.340$ \\
\hline Wald Test $(d f=232)$ & $14,333.670 * * *$ & $14,009.720 * * *$ & $|3,34| .730 * * *$ \\
\hline Logrank Test $(d f=232)$ & $30,134.240 * * *$ & $26,497.920 * * *$ & $25,256.100 * * *$ \\
\hline Score (Logrank) Test $(d f=232)$ & $46,350.150 * * *$ & $38,869.900 * * *$ & $36,044.290 * * *$ \\
\hline
\end{tabular}

Note. This table presents the regression coefficients for Cox Proportional Hazard model applied to a sample of hotels between 1990 and 2017. Change in hotel's affiliation is the hazard. Quantities in the parentheses signify the standard errors unless specified otherwise. ROOMS = Number of rooms; FLOORS = Number of floors. The following dummy variables signify the respective hotel types or amenities provided: RESTAURANT, CONVENTION, SPA, BOUTIQUE, ALLSUITE. The following dummy variables signify the location type of a hotel: Airport (reference group), Interstate, Resort, Small Metro/Town, Suburban, Urban; NX = number of times a hotel changed its affiliation before the most recent change during the sample period; ENTROPY = a historical measure of a hotel's affiliation stability weighted by recency; AGE = age of a hotel (in years) at the time of its affiliation change; EXSCALE = dummy variable for the previous scale from which the affiliation changed (reference group: Independent); NCREIFREGION = dummy variable for regional classification: EN = East North-Central: reference group; ME = Mid-East; NE = Northeast; SE = Southeast; SW = Southwest; WM = Mountain; WN = West North-Central; WP = Pacific. The following variables refer to the regional-level hotel returns data corresponding to the quarter when a hotel changed affiliation: NPI = NCREIF Commercial Property Index; IR = income return; AR $=$ appreciation return. The following data refer to the national level financial/real estate indices corresponding to the quarter when a hotel changed affiliation: MKT = Return on the Standard \& Poor's (S\&P) 500 Index in excess of the risk-free rate; TERM = Yield spread between I0-Year Treasury Bond and the risk-free rate; DEFAULT = Yield spread between Moody's BAA-rated Corporate bonds and the risk-free rate; VIX = Chicago Board Options Exchange [CBOE]'s Option-pricing-based Volatility Index for the Stock Market; NPI = Return on NCREIF Commercial Property Index. The Risk-free rate is defined as the yield on 3-Month Treasury Bill. NCREIF = National Council of Real Estate Investment Fiduciaries.

$* * *, * *$, and $*$ signify statistical significance at $1 \%, 5 \%$, and $10 \%$ levels, respectively.

positive and significant parameter. As a result, we find that all the classes of chains are more likely than independent hotels to rebrand. Boutique hotels and big hotels confirm their tendency to change. Financial variables including VIX and TERM affect in a positive and significant way the probability to rebrand, exactly as in our baseline model. The return on commercial property index (NPI) is also significant and positively affects rebranding. Exactly as in our baseline model, the AR is positive for the three subsamples and the interaction with uncertainty (VIX) mitigates its positive effect.

\section{Prediction}

In this section, we analyze the predictive ability of our models. Survival analysis is semiparametric in nature and characterized by censored data, which renders it less useful for prediction. Therefore, we use Accelerated Failure Time (AFT) models to build a tool that practitioners can use to calculate the survival duration of a hotel's brand. We also develop Logit models to test the predictive ability of our regressors. These models predict the likelihood of a hotel to change its brand. The Logit prediction results are presented in the appendix. ${ }^{22}$

\section{Practical Application Using Predictive Models for the Survival of an Affiliation}

Our analyses above present robust evidence that the survival duration of a brand can vary drastically across asset 
Table 6.

Prediction of Affiliation Survival Duration Based on Asset Characteristics: Some Examples.

\begin{tabular}{|c|c|c|c|c|}
\hline \multirow{2}{*}{$\begin{array}{l}\text { Attribute } \\
\text { Scale }\end{array}$} & \multirow{2}{*}{$\frac{\text { Coefficients }}{1.399}$} & \multirow[t]{2}{*}{ Hotel A } & \multirow[t]{2}{*}{ Hotel B } & \multirow[t]{2}{*}{ Hotel C } \\
\hline & & & & \\
\hline Constant & 6.364 & I & 1 & I \\
\hline NX & -3.604 & 0 & 2 & 3 \\
\hline$N X^{2}$ & 0.884 & 0 & 4 & 9 \\
\hline \multicolumn{5}{|c|}{$\begin{array}{l}\text { Scale } \\
\text { (Reference Group = “Independent") }\end{array}$} \\
\hline Economy Chains & -0.771 & 0 & 0 & 0 \\
\hline Luxury Chains & -0.762 & 0 & 0 & 1 \\
\hline Midscale Chains & -0.983 & 1 & 0 & 0 \\
\hline Upper Midscale Chains & -0.721 & 0 & 0 & 0 \\
\hline Upper Upscale Chains & -0.476 & 0 & 0 & 0 \\
\hline Upscale Chains & 0.111 & 0 & 1 & 0 \\
\hline ROOMS & -0.0003 & 200 & 300 & 300 \\
\hline FLOORS & -0.0256 & 5 & 10 & 1 \\
\hline \multicolumn{5}{|l|}{$\begin{array}{l}\text { Location Classification } \\
\text { (reference Group = "Airport”) }\end{array}$} \\
\hline Interstate & -0.184 & 0 & 0 & 0 \\
\hline Resort & 0.509 & 0 & 0 & 1 \\
\hline Small Metro/Town & 0.082 & 0 & 0 & 0 \\
\hline Suburban & -0.041 & 0 & 0 & 0 \\
\hline Urban & 0.369 & 0 & I & 0 \\
\hline CONVENTION & 0.126 & 0 & 1 & 1 \\
\hline BOUTIQUE & -0.906 & I & 0 & 0 \\
\hline ALLSUITE & -0.207 & 0 & 0 & 0 \\
\hline \multicolumn{5}{|l|}{$\begin{array}{l}\text { Region } \\
\text { (Reference Group = “EN”) }\end{array}$} \\
\hline ME & -0.213 & 0 & 0 & 1 \\
\hline NE & 0.011 & 0 & 0 & 0 \\
\hline SE & -0.349 & 0 & 1 & 0 \\
\hline sW & -0.376 & 0 & 0 & 0 \\
\hline WM & -0.025 & 0 & 0 & 0 \\
\hline WN & -0.627 & I & 0 & 0 \\
\hline WP & -0.263 & 0 & 0 & 0 \\
\hline$X_{i} \beta$ & & 3.06 & 2.603 & 3.052 \\
\hline$e^{(x, \beta)}$ & & 38.86 & 13.50 & 21.17 \\
\hline$(\ln 2)^{\text {scale }}$ & & 0.60 & 0.60 & 0.60 \\
\hline Median Spell $=(\ln 2)^{\text {scale }} \cdot e^{(X, B)}$ & & 23.27 & 8.09 & 12.68 \\
\hline
\end{tabular}

Note. The parameters are derived from Accelerated Failure Time (AFT) models assuming a Weibull distribution. NX = number of times a hotel changed its affiliation before the most recent change during the sample period; EN = East North-Central (reference group); ME = Mid-East; NE = Northeast; SE = Southeast; SW = Southwest; WM = Mountain; WN = West North-Central; WP = Pacific.

characteristics and market conditions. Logistic models can predict the binary hazard of rebranding versus not, but do not predict the survival time of a brand. Similarly, the proportional hazard models - due to their semiparametric nature-are useful in predicting hazard probability, but not the survival duration. In this section, we emphasize predicting the survival time of a brand. The predictive model could be considered to predict how long (in years) the existing brand of the hotel will survive until it is changed to something else, based on the hotel's current characteristics and past record of rebranding. In other words, it predicts the survival duration of a hotel's brand based purely on its "inherent" characteristics and its past rebranding record. 


\section{Accelerated Failure Time (AFT) Model}

The parametric AFT models explain how the survival duration of an affiliation is determined by a set of predictor variables. If $T$ is the survival duration and $X$ is a vector of asset attributes,

$$
T=\mathrm{Y} \cdot e^{\left(\beta_{0}+\beta_{1} X\right)},
$$

where $\beta_{0}$ and $\beta_{1}$ are AFT regression parameters. $\gamma$ is a composite parameter ${ }^{23}$ suggested by the AFT model. Empirically,

$$
\operatorname{Ln}(T)=B_{0}+C X+\sigma \epsilon
$$

where, $B_{0}$ and $B$ are regression coefficients, and $\epsilon$ is the random error term such that $\mathrm{e}=\sigma \epsilon$ and $\mathrm{e}$ is i.i.d. from $N(0$, $\left.\sigma^{2}\right)$. Therefore, $\sigma$ is the "scale parameter" when fitting a Weibull model to survival duration. Mathematically, for specific asset $i$, the median duration of affiliation survival (SPELL) can be estimated by applying the following function:

$$
\text { MedianSPELL }_{i}=(\ln 2)^{\text {scale }} \cdot \mathrm{e}^{\left(X_{i} B\right)} .
$$

In Table 6, we present the parameters derived from a parsimoniously specified AFT. Our objective is to predict the ex ante median survival duration of an affiliation (SPELL) based on an asset attribute. For example, one might be interested in estimating when the current affiliation will change in the future. As such, the current market conditions (when the rebranding takes place), and the age of the asset - at the time of rebranding - are irrelevant. Also, for practical reasons, we remove market identifiers from the predictive models, which may, otherwise, lead to a very large number of coefficients. Effectively, in the "Parsimonious" model, we include fewer variables to explain via examples, how such models could be used for prediction. This model, whose parameter estimates are presented in Table 6, offers an easy tool to predict the median affiliation duration on the equation above. For illustration purposes, let us consider three specific assets with the following characteristics, right after assuming a new affiliation:

Hotel A: Currently affiliated with a midscale chain, this 200room, 5-floor airport hotel never changed its affiliation in the past $(\mathrm{NX}=0)$. This Boutique hotel does not fall into convention or all-suite hotel classifications and is located in the WestNorth-Central region. The predicted survival time for the current brand is nearly 23 years.

Hotel B: Currently affiliated with an upscale chain, this 300room, 10-floor urban hotel changed its affiliation twice in the past. This convention hotel is not classified either as boutique or all-suite hotel and is located in the Southeast region. The predicted survival time for the current brand is nearly 8 years.
Hotel C: Currently affiliated with a luxury chain, this 300room, 1-floor resort hotel changed its affiliation thrice in the past. This convention hotel is neither classified as boutique nor as an all-suite hotel and is located in the Mid-East region. The predicted survival time for the current brand is nearly 13 years.

The first column provides a parametric estimation of coefficients from an AFT model. We provide coefficients for the complete set of variables included in the AFT model. One can code the information about the three hotels into the variables as shown in the last three columns. For each hotel, we set the "Constant" as 1 to include the effect of the intercept into estimation. For each hotel, $X_{i} \beta$ is calculated as the sum-product of the array of parameters and the array of hotel attributes, as coded. The last row shows the median holding period estimation for each of the three example hotels. One can use Table 6 to calculate the median survival duration of an affiliation (SPELL) of a hotel with a known set of attributes as required by the model.

\section{Conclusion}

Rebranding is an important strategic choice for a hotel owner. Several reasons can explain rebranding, such as a change in business model, a franchisor/franchisee disagreement, changes in franchise fees, the need to address a shift in the local demand, or simply the expiration of an existing franchise contract. The brand change may also be initiated by the franchise owner in cases where they intend to sell "noncore or non-profitable" hotels, or wish to "de-flag" hotels that fail to meet the "current brand's promise."

Unlike the existing literature, in this study, we focus our attention on the causes rather than on the effects of rebranding. In particular, rather than proprietary financial information, we focus on the asset information that is easily available and observable and show that such information suggests an "inherent" propensity of an asset to rebrand. We also include market and industry performance indicators and show their significant effect on rebranding of hotels. The age of the property, the history of rebrandings, as well as the scale and type of hotel, significantly affect the choice of rebranding. Financial performance indicators for the market and for the specific industry also appear important in our analysis. Optimism brings about an increased propensity to rebrand. Notably, we observe that properties' appreciation especially induces independent hotels to move toward a brand and branded hotels to change brand.

Our findings provide strong evidence in favor of the argument that a hotel's physical attributes lead to an inherent rebranding propensity, which is further influenced by macroeconomic factors. In general, rebranding is associated with a higher degree of confidence and opportunism: Larger, taller, and chain-affiliated hotels tend to rebrand more often. Bull runs in the stock market (MKT and VIX), 
debt market (TERM), and hotel market financial performance (AR, IR) induce rebranding activity. Larger and taller hotels have a higher tendency to upscale and a lower tendency to downscale. Besides, rebranding is higher at the extremes of hotel classes (i.e., economy and luxury) segments rather in the mid-segments, as these (extreme) segments tend to be larger, providing superior opportunities to rebrand. As hotels grow older, they have a lower tendency to switch brand affiliation to a different chain, exhibiting a degree of maturation with the existing brand identity. However, branded hotels have an increased tendency to turn independent with age, or to be rebranded within a chain.

After explaining the determinants of affiliation change using semiparametric proportional hazard models, we run parametric AFT models for prediction to emphasize the practical relevance of our study. Our parsimonious AFT model can be easily used by industry professionals. Through some examples, we show how to apply the AFT model to estimate a brand's duration.

Hotel chains could apply this model to predict the rebranding (within or across chains; from independent to brand, and vice versa), upscaling, and downscaling of individual hotels. Besides, the AFT models help predict the brand survival duration of a specific hotel. These findings will be useful in identifying target hotels that a brand could consider, or the hotel at risk of moving to another brand. The AFT models will also help the chains in valuing brand contracts by providing an informed estimate of how long a brand contract is likely to survive.

\section{Limitations and Future Research}

Our study provides robust evidence that a hotel has a strong "inherent" tendency to rebrand based on its observable, physical characteristics; but it is not without its limitations. Our argument that financial performance is determined by the same factors as included in our models is backed by the literature. However, future studies could include financial performance in the models to validate the findings. Hotel chains compete with each other for their respective brand "flags." Their relative performance could also play a role in being selected by an owner. Future studies could focus on this aspect of rebranding.

Another limitation of our study is that we focus uniquely on the supply-side of the market. It would be interesting in the future to emphasize the role of the demand-side, which also contributes to the financial performance of a property, and analyze how consumers react in front of affiliation changes, and whether market variables and property features are correlated with that reaction.

Finally, our dataset includes U.S.-based hotels only. Future studies could include an international scope. Different motivations for brand changes, such as those driven by owners (including those in conjunction with sales transactions) and those driven by franchisors at the termination of franchise contracts (which are less important in the context of the current research) are another area for future research.

\section{Appendix}

\section{Entropy: The Recency-Weighted Measure of Past Disarray in Brand Affiliation}

In our sample, the average survival time of an affiliation is 13 years. From an owner's or franchisor's standpoint, the past record of affiliation change in a hotel could signal the property's unobserved characteristics that could influence its propensity toward changing the affiliation in the future. The recent affiliation changes, in particular, will influence such a propensity stronger than the older ones. However, the hotels in our sample exhibit a wide range of characteristics with respect to the affiliation change in terms of how many times they occurred, how closely clustered were the changes over time, and how far back in the past were the changes. We develop a measure of affiliation change disarray that broadly mimics the "entropy" measure usually applied in social sciences and physics.

Suppose a given hotel witnessed $N$ affiliation changes before the most recent change observed in its lifetime (i.e., $i=1$ to $N, 1$ denoting the one immediately before the recent change, and $N$ the earliest change recorded). $r_{i}$ is the recency measure, which reflects how many years before the most recent change did the $i$ th change take place. $l_{i}$ is the survival time for the $i$ th affiliation.

Thus, $r_{1}=l_{1}, r_{2}=l_{1}+l_{2}$ and so on.

The perceived degree of disarray in brand affiliation will be inversely proportional to how long a brand survives. The marginal impact of the disarray will diminish with the increase in the survival age of an affiliation (e.g., the perceived difference of disarray between 2 years and 3 years is much higher compared with the disarray between 100 years and 101 years of affiliation survival). Besides, a market participant will measure the disarray in terms of the average age of an affiliation survival, thus, treating 13 years as a base estimate. Therefore,

$$
\Omega \alpha \log _{13}\left(\frac{13}{l_{i}}\right)
$$

If an affiliation survives exactly for 13 years, it leads to no disarray, $\log (1)=0$. For $1>13$, the disarray is negative. For $1<13$, the disarray is positive.

In addition, the perceived degree of disarray in brand affiliation $(\Omega)$ will be stronger in recently perceived changes. Also, the effect of recency will marginally diminish over time ( $k$ years earlier from today will have a much stronger impact on the memory compared with $k$-years earlier 5 decades ago). Also, participants will benchmark the survival of an affiliation in terms of a standard 
affiliation age (i.e., 13 years) and will use this estimate as the base.

$$
\Omega \alpha \frac{1}{\log _{13}\left(r_{i}\right)} .
$$

For $r>13$, the above measure $<1$. However, a mathematical challenge with this measure is that the denominator will be zero when $r=1$. Therefore, we modify the relationship as,

$$
\Omega \propto \frac{1}{1+\log _{13}\left(r_{i}\right)} .
$$

The denominator will equal zero only for a unique value of $r$. We do not have any observations with that value in our sample (i.e., brand survival $<1$ month).

We posit the latter measure as the "recency" weight. Thus, the partial contribution of a particular past affiliation of a hotel to its degree of affiliation disarray could be shown as,

$$
\Omega_{i}=\log _{13}\left(\frac{13}{l_{i}}\right) \times \frac{1}{1+\log _{13}\left(r_{i}\right)}
$$

And the total measurement of affiliation disarray given the history of a hotel is,

$$
\sum_{i=1}^{4} \log _{13}\left(\frac{13}{l_{i}}\right) \times \frac{1}{1+\log _{13}\left(r_{i}\right)}
$$

We include up to the past four brand changes (excluding the most recent one) in our calculation due to data limitations. STR Global only provides up to the previous four affiliations. However, given the average age of 13 years per affiliation, the oldest change is typically half a century old. Therefore, changes before that should have minimal influence on the perceived brand disarray, if at all. For several properties, the original affiliation is different from the earliest subsequent affiliation reported by STR. In such cases, we estimate the midpoint between the hotel start date and the earliest subsequent affiliation date and synthetically assume an affiliation change at that point. For the reasons mentioned above, the error infused by such an approximation should be negligible.

\section{Survival and Hazard Functions}

Suppose $t$ represents a point in the lifetime of a hotel, and $T$ denotes the survival duration of an affiliation. $f(t)$ and $F(t)$ are the probability density function (pdf) and cumulative distribution function (cdf) of $T$, such that

$$
\frac{\mathrm{d} F(t)}{\mathrm{d} t}=f(t) \text {. }
$$

Suppose $F(t)=P(T<t)$ is the probability that the prepayment hazard has occurred by its age $t$.
Thus, $F(t)=\int_{0}^{t} f(x) \mathrm{d}(x)$. Note that $t$ is measured on discrete intervals, however, for econometric purposes, it is assumed to be a continuous function in time.

The survival function $S(t)$ denotes the probability that the affiliation survived beyond a hotel's age $t$. $S(t)$ is the probability that the hotel affiliation was not changed until the hotel reached the age $t$.

$$
S(t)=P(T \geq t)=1-F(t)=\int_{t}^{\infty} f(x) \mathrm{d} x
$$

which implies that,

$$
\frac{\mathrm{d} S(t)}{\mathrm{d} t}=-f(t)
$$

The Kaplan-Meier curve plots are popular in depicting such baseline survival functions. A hazard function describes the instantaneous probability for the hazard (affiliation change) to occur at age $t$, given the affiliation survives until then:

$$
h_{0}(t)=\lim _{d t \rightarrow o} \frac{P(t \leq T<t+\mathrm{d} t \mid T \geq t)}{\mathrm{d} x}
$$

Given the condition that an affiliation survived until the hotel age $t$,

$$
\begin{gathered}
h_{0}(t)=\frac{f(t)}{S(t)} \\
\Rightarrow h_{0}(t)=-\frac{\mathrm{d}}{\mathrm{d} t}\{\log [S(t)]\}
\end{gathered}
$$

The above equation is the baseline hazard rate model. However, these are nonparametric descriptions of a sample. Applying the Cox Proportional Hazard (CPH) model, we can explain the hazard function using covariates $(X)$ beyond the hotel age $(t)$ :

$$
h(t \mid X)=h_{0}(t) e^{\beta X}
$$

$\mathrm{CPH}$ models do not require specification of the nonparametric baseline hazard function, $h_{0}(t)$. However, the parameters $(\beta)$ can be estimated using partial likelihood estimators. In such a modeling framework, the hazard rate across two hotels (say, $p$ and $q$ ) across different ages $(t)$ will maintain the same ratio (i.e., $h_{p}(t) / h_{q}(t)$ is a constant). As a result, the $\mathrm{CPH}$ model is considered as a semiparametric proportional hazard model.

\section{Logit Prediction Model}

In a binary response model framework, the dependent variable associated to the rebranding decision (REBRANDING) equals 1 if the event occurs. In the logit model, we look at the probability of rebranding, given all the exogenous variables identified in the baseline analysis: 
Table A1.

Logit Prediction Models for the Most Recent Affiliation Change.

\begin{tabular}{|c|c|c|}
\hline \multirow[b]{2}{*}{ Variable } & $\begin{array}{c}\text { Full } \\
\text { Sample }\end{array}$ & $\begin{array}{c}\text { Random Training } \\
\text { Sample }(75 \%)\end{array}$ \\
\hline & (I) & $(2)$ \\
\hline \multirow[t]{2}{*}{ AGE } & $0.001 * * *$ & $0.001 * * *$ \\
\hline & $(0.0001)$ & $(0.0001)$ \\
\hline \multirow[t]{2}{*}{ ENTROPY } & $0.127 * * *$ & $0.134 * * *$ \\
\hline & $(0.002)$ & $(0.003)$ \\
\hline \multirow[t]{2}{*}{ ENTROPY ${ }^{2}$} & $-0.032 * * *$ & $-0.017^{* * *}$ \\
\hline & $(0.001)$ & $(0.001)$ \\
\hline \multirow[t]{2}{*}{ Economy } & $0.106 * * *$ & $0.138 * * *$ \\
\hline & $(0.004)$ & $(0.006)$ \\
\hline \multirow[t]{2}{*}{ Luxury } & $0.069 * * *$ & $0.04 I *$ \\
\hline & $(0.016)$ & $(0.022)$ \\
\hline \multirow[t]{2}{*}{ Midscale } & $0.116 * * *$ & $0.110 * * *$ \\
\hline & $(0.005)$ & $(0.007)$ \\
\hline \multirow[t]{2}{*}{ Upper Midscale } & $0.084 * * *$ & $0.05 \mathrm{I} * * *$ \\
\hline & $(0.004)$ & $(0.006)$ \\
\hline \multirow[t]{2}{*}{ Upper Upscale } & $0.085 * * *$ & $0.064 * * *$ \\
\hline & $(0.009)$ & $(0.012)$ \\
\hline \multirow[t]{2}{*}{ Upscale } & $0.060 * * *$ & 0.001 \\
\hline & $(0.005)$ & $(0.008)$ \\
\hline \multirow[t]{2}{*}{ ROOMS } & $0.00004 * * *$ & $0.0001 * * *$ \\
\hline & $(0.00001)$ & $(0.00002)$ \\
\hline \multirow[t]{2}{*}{ FLOORS } & $0.001 * *$ & 0.0003 \\
\hline & $(0.00 I)$ & $(0.00 I)$ \\
\hline \multirow[t]{2}{*}{ Interstate } & $0.029 * * *$ & $0.02 I^{* *}$ \\
\hline & $(0.008)$ & $(0.01 \mathrm{I})$ \\
\hline \multirow[t]{2}{*}{ Resort } & -0.011 & $-0.023^{* *}$ \\
\hline & $(0.009)$ & $(0.012)$ \\
\hline \multirow[t]{2}{*}{ Small Metro/Town } & $0.020 * * *$ & 0.0003 \\
\hline & $(0.007)$ & $(0.010)$ \\
\hline \multirow[t]{2}{*}{ Suburban } & 0.010 & 0.014 \\
\hline & $(0.007)$ & $(0.009)$ \\
\hline \multirow[t]{2}{*}{ Urban } & $-0.015^{* *}$ & -0.006 \\
\hline & $(0.008)$ & $(0.011)$ \\
\hline \multirow[t]{2}{*}{ CONVENTION } & $0.024 * *$ & 0.014 \\
\hline & $(0.012)$ & $(0.017)$ \\
\hline \multirow[t]{2}{*}{ BOUTIQUE } & $0.091 * * *$ & $0.115^{* * *}$ \\
\hline & $(0.009)$ & $(0.013)$ \\
\hline \multirow[t]{2}{*}{ ALLSUITE } & $-0.018 * * *$ & $-0.03 I^{* * * *}$ \\
\hline & $(0.004)$ & $(0.005)$ \\
\hline \multirow[t]{2}{*}{ MKT } & $0.001 * *$ & $0.004 * * *$ \\
\hline & $(0.0005)$ & $(0.001)$ \\
\hline \multirow[t]{2}{*}{ TERM } & $0.116 * * *$ & $0.136 * * *$ \\
\hline & $(0.007)$ & $(0.003)$ \\
\hline \multirow[t]{2}{*}{ VIX } & $0.011 * * *$ & $0.040 * * *$ \\
\hline & $(0.00 \mathrm{I})$ & $(0.00 I)$ \\
\hline \multirow[t]{2}{*}{ NPI } & $0.044 * * *$ & $0.097^{* * * *}$ \\
\hline & $(0.004)$ & $(0.002)$ \\
\hline
\end{tabular}

(continued)
Table AI. (continued)

\begin{tabular}{|c|c|c|}
\hline & $\begin{array}{c}\text { Full } \\
\text { Sample }\end{array}$ & $\begin{array}{l}\text { Random Training } \\
\text { Sample }(75 \%)\end{array}$ \\
\hline Variable & (I) & $(2)$ \\
\hline \multirow[t]{2}{*}{ IR } & $3.110 * * *$ & $7.710 * * *$ \\
\hline & $(0.665)$ & $(0.896)$ \\
\hline \multirow[t]{2}{*}{ AR } & $1.574 * * *$ & $2.894 * * *$ \\
\hline & $(0.137)$ & $(0.164)$ \\
\hline \multirow[t]{2}{*}{$\mathrm{VIX} \times \quad \mathrm{AR}$} & $-0.04 I^{* * *}$ & $-0.030 * * *$ \\
\hline & $(0.005)$ & $(0.006)$ \\
\hline \multirow[t]{2}{*}{$\mathrm{VIX} \times \mathrm{IR}$} & $-0.096 * * *$ & $-0.167 * * *$ \\
\hline & $(0.034)$ & $(0.046)$ \\
\hline \multirow[t]{2}{*}{ Constant } & $-0.54 I * * *$ & $-0.730 * * *$ \\
\hline & $(0.075)$ & $(0.075)$ \\
\hline Monthly Seasonality & Yes & No \\
\hline Annual Trend & Yes & No \\
\hline NCREIF Region & Yes & Yes \\
\hline Metro Markets & Yes & Yes \\
\hline$N$ & $43,04 I$ & 32,280 \\
\hline Log Likelihood & $-3,476.537$ & $-9,135.835$ \\
\hline Akaike Inf. Crit. & $7,421.073$ & $18,663.670$ \\
\hline
\end{tabular}

Note. This table presents the regression coefficients for Logit models applied to a sample of hotels between 1990 and 2017. The training sample comprises randomly selected $75 \%$ observations. Change in hotel's affiliation is the binary dependent variable. Quantities in the parentheses signify the standard errors unless specified otherwise. ROOMS = number of rooms; FLOORS = number of floors. The following dummy variables signify the respective hotel types or amenities provided: RESTAURANT, CONVENTION, SPA, BOUTIQUE, ALLSUITE. The following dummy variables signify the location type of a hotel: Airport (reference group), Interstate, Resort, Small Metro/Town, Suburban, Urban; NX = number of times a hotel changed its affiliation before the most recent change during the sample period; ENTROPY = a historical measure of a hotel's affiliation stability weighted by recency; AGE = age of a hotel (in years) at the time of its affiliation change; EXSCALE = dummy variable for the previous scale from which the affiliation changed (reference group: Independent); NCREIFREGION = dummy variable for regional classification: $\mathrm{EN}=$ East North-Central: reference group; $\mathrm{ME}=$ MidEast; NE = Northeast; SE = Southeast; SW = Southwest; WM = Mountain; WN = West North-Central; WP = Pacific. The following variables refer to the regional-level hotel returns data corresponding to the quarter when a hotel changed affiliation: NPI = NCREIF Commercial Property Index; IR = income return; AR = appreciation return. The following data refer to the national level financial/real estate indices corresponding to the quarter when a hotel changed affiliation: MKT $=$ Return on the Standard \& Poor's (S\&P) 500 Index in excess of the risk-free rate; TERM = Yield spread between 10Year Treasury Bond and the risk-free rate; DEFAULT = Yield spread between Moody's BAA Corporate bonds and the risk-free rate; VIX = CBOE's Option-pricing-based Volatility Index for the Stock Market; NPI = Return on NCREIF Commercial Property Index. The riskfree rate is defined as the yield on 3-Month Treasury Bill. NCREIF = National Council of Real Estate Investment Fiduciaries. $* * *, * *$, and $*$ signify statistical significance at $1 \%, 5 \%$, and $10 \%$ levels, respectively. 
Table A2.

Sample Accuracy (Correlation of Predicted and Actual Status of Affiliation Change).

\begin{tabular}{|c|c|c|}
\hline Model type & Test Sample & Correlation \\
\hline \multirow[t]{24}{*}{ Logit } & Random 25\% & .66 \\
\hline & Market Subsamples & \\
\hline & Los Angeles, CA, Market & .74 \\
\hline & Houston, TX, Market & .69 \\
\hline & Atlanta, GA, Market & .73 \\
\hline & Kauai Islands, HI, Market & .50 \\
\hline & Madison, WI, Market & .69 \\
\hline & Lexington, KY, Market & .87 \\
\hline & Alaska & .50 \\
\hline & Cincinnati, $\mathrm{OH}$ & .67 \\
\hline & Seattle, WA & .72 \\
\hline & Kansas City, MO & .05 \\
\hline & Grand Rapids, MI & .75 \\
\hline & Ex-Parent Company ${ }^{\mathrm{a}}$ & \\
\hline & Independent Hotels & .55 \\
\hline & Parent I & .68 \\
\hline & Parent 2 & .67 \\
\hline & Parent 3 & .76 \\
\hline & Parent 4 & .74 \\
\hline & Parent 5 & .12 \\
\hline & Parent 6 & .80 \\
\hline & Parent 7 & .87 \\
\hline & Parent 8 & .89 \\
\hline & Parent 9 & .72 \\
\hline
\end{tabular}

Note. This table approximates the accuracy of the predictive abilities of affiliation choice models presented in this study. The predictions are based on the state of an observation as on the last date of data collection (or the most recent affiliation change). All models are trained on randomly selected $75 \%$ observations. For Cox Proportional Hazard models, correlation of survival time predicted by the models (as on the most recent date of data recording) is reported. Such a prediction, however, is prone to censorship in data. For Logit models, first, the predicted probability of affiliation change is estimated for each test observation and converted to binary values such that a probability $>0.5$ becomes I (i.e., affiliation change is predicted) and other predictions are treated as 0 (i.e., no change to affiliation is predicted).

a The Parent company names are redacted due to data confidentiality reasons.

$$
\operatorname{Pr}(\text { AFFILIATION CHANGE }=1 \mid X)=\mathrm{G}(X \beta)
$$

Here, $\mathrm{X}$ is the vector containing all the explanatory variables associated to the decision of changing brand, and $G$ is the logistic function:

$$
G(X \beta)=\frac{e^{X \beta}}{1+e^{X \beta}}
$$

In Table A1, we show the results of the logit estimation. In the first column, we use the full sample consisting of 43,041 observations, while in Column 2, we use a random training sample representing $75 \%$ of our total sample
$(N=32,280)$. The results in the two columns are consistent, despite the different samples. In addition, these results are aligned with the results coming from the $\mathrm{CPH}$ model. Having established the robustness of our results across different models and samples, we study the predictive power of our model. To do so, we use the estimations obtained using the training sample, and we measure the correlations between the predicted and actual status of affiliation change, based on the validation sample composed of the remaining $25 \%$ of our original sample. We attributed a value of 1 to our prediction, whenever the probability calculated by the model was larger than .05 . The prediction results are shown in Table A2.

Our predictions present a correlation of $66 \%$ with the actual status of affiliation change. To delve deeper into the analysis, we focused our attention on special features, including hotel locations and the identity of the business model before the last change. First, we included some big markets like Los Angeles, Houston, and Atlanta, and, next to them, some smaller ones, like Madison and Alaska. We observe that our predictions are more accurate in relatively larger markets implying a superior predictability in affiliation change. When we specifically focus on the business model of a hotel before the last re-affiliation, ${ }^{24}$ our model has a broadly stronger predictive power for hotels belonging to groups, rather than for independent hotels. In general, hotels' observable features and market variables reveal rebranding strategies. Some parent companies (i.e., five) display a low degree of predictability compared with others.

\section{Acknowledgments}

Authors are thankful to Steve Hood and Duane Vinson from STR/ CoStar Global for their generous data support. Our sincere thanks to Remy Rein for his insightful inputs on hotel brand dynamics and to Andrew Brenner for copyediting.

\section{Declaration of Conflicting Interests}

The author(s) declared no potential conflicts of interest with respect to the research, authorship, or publication of this article.

\section{Funding}

The author(s) received no financial support for the research, authorship, or publication of this article.

\section{ORCID iD}

Prashant Das iD https://orcid.org/0000-0002-3628-7213

\section{Notes}

1. Corgel et al. (2015); Das et al. (2017); Robinson et al. (2016).

2. http://www.hotelnewsnow.com/articles/19145/ How-long-does-a-brand-last 
3. The opposite phenomenon (wherein a chain-affiliated hotel adopts an independent brand) has also been on the rise: from 42 hotels $(5,882$ rooms) in 1992 to 280 hotels $(28,002$ rooms) in 2017 . Yet, the net effect is that the number of hotels adopting chain-affiliated brands has been on the rise.

4. According to our sample, in terms of numbers, the trend has multiplied sixfold: from 49 hotels (7,962 rooms) in 1992 to 296 hotels (31,000 rooms) in 2017.

5. With respect to total existing supply.

6. See Brady and Conlin (2004); Corgel et al. (2015); Das et al. (2017); Robinson et al. (2016); Robinson and Singh (2019); Tsai et al. (2015).

7. Our estimates are based on annual reports of six large, publicly traded chains. The data suggest nearly $\$ 1,200$ cash flow per branded room in 2018 on average. We assume a modest annual growth of $2 \%$ in the cash flow capitalized over 20 years, contract rate at $10 \%$ cost of capital.

8. According to our analysis of the STR Global Census data, the number of rebranded hotels multiplied sevenfold in 25 years: from 166 hotels $(21,912$ rooms $)$ in 1992 to 1,100 hotels (110,854 rooms) in 2017.

9. See Corgel et al. (2015); Das et al. (2017); Robinson et al. (2016); Robinson and Singh (2019); Das and Wiley (2014).

10. In this article, we focus our attention on the supply-side of the market, and we consider a partial equilibrium model. Nevertheless, as underlined by Dioko et al. (2013), the consumption-side of the market is also fundamental to understand the choice of rebranding.

11. Many of these properties were parts of consolidation (e.g., Marriott's acquisition of Starwood), which led to brand change.

12. Based on earlier studies such as Das et al. (2015).

13. The National Council of Real Estate Investment Fiduciaries (NCREIF) is a consortium of commercial property owners who participate in sharing their asset-level financial and valuation data. NCREIF develops local-level indices of these performance indicators. NCREIF data have been widely applied to numerous influential academic studies.

14. Our data collection ends on December 15, 2017. Several hotels, which did not experience rebranding until this date, may possibly be rebranded later, but those hazards are absent from our records. Such observations are termed as "censored" in the survival analysis framework.

15. See the appendix for further details on this composite measure.

16. See the appendix for a more detailed description of survival and hazard functions.

17. However, in Table 2, we show that this result about luxury classes is reverted once we control for other factors.

18. $1.440 \times \mathrm{NX}-0.326 \times \mathrm{NX}^{2}=-0.326(\mathrm{NX}-2.2)^{2}+1.577$

19. $0.597 \times$ ENTROPY $-0.137 \times$ ENTROPY $^{2}=$ $-0.137(\text { ENTROPY }-2.17)^{2}+0.645$

20. Return on NCREIF commercial property index (NPI).

21. In Cox proportional hazard framework, all model specifications include the full sample of data. However, changes of the types other than being analyzed are censored by the algorithm.

22. See Appendix Tables A1 and A2.
23. Determined by the Accelerated Failure Time (AFT) model as a composite of estimation error, the quantile of the predicted (median) SPELL, and the scale factor (unique to an AFT model specification).

24. For privacy reasons, we cannot reveal the names of the parent companies, and, therefore, we just randomly numbered them.

\section{References}

Ambrose, B. W., Sanders, A. B., \& Yavas, A. (2016). Servicers and mortgage-backed securities default: Theory and evidence. Real Estate Economics, 44(2), 462-489. http://doi. org/10.1111/1540-6229.12099

Blal, I., \& Graf, N. S. (2013). The discount effect of non-normative physical characteristics on the price of lodging properties. International Journal of Hospitality Management, 34, 413-422.

Bradley, D., Pantzalis, C., \& Yuan, X. (2016). The influence of political bias in state pension funds. Journal of Financial Economics, 119(1), 69-91. http://doi.org/10.1016/j.jfineco. 2015.08.017

Brady, P. J., \& Conlin, M. E. (2004). The performance of REITowned properties and the impact of REIT market power. The Journal of Real Estate Finance and Economics, 28, 1. https:// papers.ssrn.com/sol3/papers.cfm?abstract_id=417783

Chen, J., \& Deng, Y. (2013). Commercial mortgage workout strategy and conditional default probability: Evidence from special serviced CMBS loans. The Journal of Real Estate Finance and Economics, 46(4), 609-632. http://doi.org/10.1007/ s11146-012-9374-Z

Corgel, J. B., Liu, C., \& White, R. M. (2015). Determinants of hotel property prices. The Journal of Real Estate Finance and Economics, 51, 415-439.

Das, P. K., \& Freybote, J. (in press). Investor sentiment and prepayment hazard: The case of multifamily MBS loans. Journal of Real Estate Research.

Das, P. K., Freybote, J., \& Marcato, G. (2015). An investigation into sentiment-induced institutional trading behavior and asset pricing in the REIT market. The Journal of Real Estate Finance and Economics, 51(2), 160-189.

Das, P., \& Wiley, J. A. (2014). Determinants of premia for energyefficient design in the office market. Journal of Property Research, 31(1), 64-86.

Das, P. K., Smith, P., \& Gallimore, P. (2017). Pricing extreme attributes in commercial real estate: The case of hotel transactions. The Journal of Real Estate Finance and Economics, 57, 264296. http://doi.org/10.1007/s11146-017-9621-4

Dev, C. S. (2015). Hotel brand conversions: What works and what doesn't. Cornell Hospitality Report, 15(21), 3-11.

Dioko, L. A. N., So, S., \& Harrill, R. (2013). Hotel category switching behavior-Evidence of mobility, stasis or loyalty. International Journal of Hospitality Management, 34(1), 234-244.

Hanson, B., Mattila, A. S. O., Neill, J. W., \& Kim, Y. (2009). Hotel rebranding and rescaling: Effects on financial performance. Cornell Hospitality Quarterly, 50(3), 360-370. http:// doi.org/10.1177/1938965509332762 
Jenter, D., \& Kanaan, F. (2015). CEO turnover and relative performance evaluation. Journal of Finance, 70(5), 2155-2184. http://doi.org/10.1111/jofi.12282

Liu, B., \& Sing, T. F. (2017). "Cure" effects and mortgage default: A split population survival time model. The Journal of Real Estate Finance and Economics, 56, 217-251. http://doi. org/10.1007/s11146-017-9597-0

Malmendier, U., Opp, M. M., \& Saidi, F. (2016). Target revaluation after failed takeover attempts: Cash versus stock. Journal of Financial Economics, 119(1), 92-106. http://doi. org/10.1016/j.jfineco.2015.08.013

O’Neill, J. W., \& Carlbäck, M. (2011). Do brands matter? A comparison of branded and independent hotels' performance during a full economic cycle. International Journal of Hospitality Management, 30(3), 515-521.

O’Neill, J. W., Hanson, B., \& Mattila, A. S. (2008). The relationship of sales and marketing expenses to hotel performance in the United States. Cornell Hospitality Quarterly, 49(4), 355-363. http://doi.org/10.1177/1938965508324634

O’Neill, J. W., \& Mattila, A. S. (2010). Hotel brand strategy. Cornell Hospitality Quarterly, 51(1), 27-34.

Robinson, S., \& Singh, A. (2019). The impact of green labels on U.S. hotel net operating income: Operating statements analyses. Journal of Sustainable Real Estate, 11, 156-173.

Robinson, S., Singh, A., \& Das, P. (2016). Financial impact of LEED and energy star certifications on hotel revenues.
The Journal of Hospitality Financial Management, 24, 110-126.

Rosiers, F., , Des Thériault, M., \& Dubé, J. (2016). Chain affiliation, store prestige, and shopping center rents. Journal of Real Estate Research, 38(1), 27-57. http://www.aresjournals.org/ doi/abs/10.5555/0896-5803.38.1.27

Tsai, Y.-L., Dev, C. S., \& Chintagunta, P. (2015). What's in a brand name? Assessing the impact of rebranding in the hospitality industry. Journal of Marketing Research, 52(6), 865878. http://doi.org/10.1509/jmr.13.0221

\section{Author Biographies}

Isabella Blengin, $\mathrm{PhD}$, is an Assistant Professor in Economics at Ecole hôtelière de Lausanne where she teaches microeconomics and hospitality economics in the bachelor and in the online MBA programs. After earning her PhDs at the University of Milano and at Boston College, she did a post-doc at the University of Lausanne. She has been visiting fellow in the economics department at MIT and summer intern at the Boston Federal Reserve.

Prashant Das has served as an Associate Professor of Real Estate Finance at EHL Lausanne (Switzerland) and joins the Indian Institute of Management (IIM) Ahmedabad faculty of Finance in 2020. Beyond serving on the academic Board of EHL Lausanne, he has been an Editorial Board member of several scholarly journals. He has earned nine internationally competitive research awards and is engaged with the industry through several consulting roles. 